\title{
Neuronal Activity in the Primate Hippocampal Formation during a Conditional Association Task Based on the Subject's Location
}

\author{
Satoshi Eifuku, Hisao Nishijo, Toshiaki Kita, and Taketoshi Ono \\ Department of Physiology, Faculty of Medicine, Toyama Medical and Pharmaceutical University, Toyama 930-01, \\ Japan
}

The hippocampal formation (HF) functions in two domains of memory: spatial and nonspatial associative memory. The HF includes the hippocampus proper, the dentate gyrus, and the subicular complex. Studies of spatial correlates of HF neuronal activity have revealed that a subject's location in space can impose critical constraints on patterns of neuronal activity in the HF. This report compares monkey HF neuronal responses in two kinds of stimulusresponse association tasks (go/no-go tasks with symmetrical reinforcement). In a place-dependent, conditional, stimulus-response association (PCA) task, the subject's location was the condition upon which stimulus (object)behavioral response association depended. In a place-independent, simple, stimulus-response association (ISA) task, the object-behavioral response contingency was independent of the subject's location.

Of 329 neurons recorded, the activity of 88 increased or decreased significantly in response to the presentation of an object during the PCA task. Responses of 17 neurons depended differentially on specific combinations of object, place, and behavior in the PCA task (specific-combination neurons). These specific-combination responses do not simply reflect object-behavioral response association in the PCA task, since neuronal responses in the same object-behavioral response association were not restored in the ISA task in which there was no dependence on the subject's location. This suggests the influence of location on HF neuronal responses in object-behavioral response association when the subject's location is imposed as a condition. Responses of 12 neurons differentiated the kind of object in the PCA task (object-differential neurons). In the ISA task, most object-differential responses diminished or disappeared. Since the HF object-differential responses occurred in all locations, these responses were probably elicited by the conditions imposed by the PCA task. Characteristics of the two neuron types suggest that HF neurons encode both stimulus percept and attributes such as

\footnotetext{
Received Aug. 8, 1994; revised Jan. 17, 1995; accepted Feb. 10, 1995.

We thank Dr. H. Eichenbaun (State Universily of New York, Stony Brook) or comments on the manuscript and Dr. A. Simpson (Showa University, Tokyo) for help in preparing the manuscript. This work was supported partly by the Japanese Ministry of Education, Science and Culture Grants-in-Aid for Scientific Research (05267103, 06454706 and 06680786), and by Uehara Memorial Foundation, and by Human Frontier Science Program for the third fiscal year.

Correspondence should be addressed to Professor Taketoshi Ono, M.D., Ph.D., Department of Physiology, Faculty of Medicine, Toyama Medical and Pharmaceutical University, Sugitani 2630, Toyama 930-01, Japan.

Copyright (C) 1995 Society for Neuroscience $0270 \sim 6474 / 95 / 154952-18 \$ 05.00 / 0$
}

the place where the stimulus is presented and the conditional relation imposed in the task.

[Key words: hippocampal formation, monkey, neuronal activity, go/no-go task, subject's location, conditional association]

The hippocampal formation (HF), which here includes the hippocampus proper, the dentate gyrus, and the subicular complex, is considered by some to be the highest stage of the association cortex. It receives the final outputs from the association cortices (Witter et al., 1989; Amaral and Insausti, 1990; Felleman and Van Essen, 1991), and is essential to some classes of memory (Squire and Zola-Morgan, 1991). Dependence of memory on the $\mathrm{HF}$ is evident in both spatial and nonspatial domains; animals and humans with selective hippocampal damage show deficits in tasks that require spatial (Morris et al., 1982; Parkinson et al., 1988; Gaffan and Harrison, 1989) or nonspatial mnemonic processes (Scoville and Milner, 1957; Mishkin, 1978; Zola-Morgan and Squire, 1990).

Single neuron studies of behaving animals have yielded neuronal correlates of HF functions, and some clues to neuronal processes in the HF have emerged. Two distinct courses of study have been followed: one is a series of studies of rat "place" cells (O'Keefe and Dostrovsky, 1971; O'Keefe and Conway, 1978; McNaughton et al., 1983; Muller and Kubie, 1987; for review, Eichenbaum et al., 1992) that are selectively active in particular locations of the subject. Some reported influence of environmental manipulation on place cell firing ( $O$ 'Keefe and Speakman, 1987; Breese et al., 1989), and some reported place cells that are temporally correlated with the subject's behavior (Wible et al., 1986; Wiener et al., 1989). Wilson and McNaughton (1993) reported that place cells may form an ensemble to represent space, and this could be used to identify the location of the animal. Recently, we reported place-related neurons in the monkey HF (Ono et al., 1991, 1993a,b) that are comparable to the rat place cells. Using a paradigm in which the monkey could change the location of a motorized movable device in which it was riding while performing an operant task, we found several neuronal types including one that changed activity when the subject changed location, and one that responded selectively to task cues, depending on the subject's location. Taken together, these studies suggest that spatial influence due to change in the subject's location is an important determinant of HF neuronal responses.

Other studies also have shown HF involvement in associative learning. If the hippocampus is damaged, there are deficits in performing tasks that require association between a particular stimulus and the location at which the stimulus is presented (Par- 
kinson et al., 1988), and association between a particular stimulus and the behavioral response that the stimulus indicated (Rupniak and Gaffan, 1987). In similar tasks, some neurons selectively responded to a specific association between a stimulus and the location in which it was presented (Rolls et al., 1989; Feigenbaum and Rolls, 1991), and responded to an association between a particular stimulus and the indicated response (Watanabe and Niki, 1985; Miyashita et al., 1989; Cahusac et al., 1993). Recently, Gaffan and Harrison (1989) showed that an $\mathrm{HF}$ lesion impairs acquisition of the task that requires a conditional stimulus (object)-response association based on the vicws of the same environmental cues from different directions. This shows a good example of HF role on relational representation of multiple factors such as environmental spatial cues, the subject's location, and behavioral responses (Eichenbaum et al., 1993).

The present study was designed to investigate HF neuronal activity of monkeys during performance of two tasks; one was a modified version of the task by Gaffan and Harrison (1989), that incorporates two important determinants, associative learning and spatial influence. The place-dependent conditional stimulus-response association (PCA) task used in the present study required conditional association of the object and the behavioral response based on the subject's location. The other was a placeindependent simple stimulus-response association (ISA) task that required simple object-behavioral response association with no relation to the subject's location. Although these two tasks are go/no-go tasks with symmetrical reinforcement, the association structure defined by the dimensions implicit in associations (e.g., number of item, whether it is conditional), was more complicated in the conditional PCA than in the ISA task. The stimulus object pair and the object-behavioral response contingencies in both tasks were identical, but object-behavioral response contingency was conditional upon place-object relations in the PCA task, and it was constant in the ISA task. Analyses of the response patterns in these two tasks should disclose the influence of the subject's location on HF neuronal responses to specific association such as particular stimulus-behavior association, and influence of association structure on HF neuronal responses.

\section{Materials and Methods}

Animals and experimental apparatus. Two male adult monkeys ( $\mathrm{Ma}$ caca fuscata), weighing 3.7 and $4.5 \mathrm{~kg}$, were used. A monkey was restrained painlessly in a stereotaxic apparatus by a surgically fixed acrylic head holder and sal in a $0.7 \times 0.8 \times 0.85 \mathrm{~m}$ high cab, which was set in a $2.5 \times 2.5 \mathrm{~m}$ field located in a $5 \times 6 \mathrm{~m}$ experimental room (Fig. 1A), as previously described (Ono et al., 1991, 1993a,b). In the present task, the monkey had no control over the movement or position of the cab. During a recording session, eye movement was monitored by electrooculograms (EOG). The room contained several readily identified landmarks, such as a stereomicroscope, a refrigerator, a table, a rack, and some experimental devices. The monkey always faced toward the right side of Figure $1 R$. The cab was moved horizontally from one location to another by electric motors under preprogrammed computer control. The front, left, and right walls of the cab were made of halfmirrored Plexiglas, and the rear wall was a steel plate symmetrically equipped with two lamps (cab lamps) and two speakers on the inside. The landmarks in the room could be seen from inside of the cab through the hall-mirrored walls when the cab lights were extinguished. The upper part of the front wall also contained a double half-mirrored 15 $\times 15 \mathrm{~cm}$ shutter just above an operant responding lever. There was an illuminated stage for object presentation behind the shutter and an object on the stage was visible to the monkey through the shutter when the stage lamp was on. Juice, controlled by an electromagnetic valve, was delivered from a tube that projected through the rear wall.

Behavioral tasks. Two kinds of symmetrically reinforced go/no-go tasks were used with the same familiar stimulus objects. The two tasks used in the experiment were stimulus-response association tasks that differed in their association structures. In the PCA task, the objectbehavioral response association was conditional upon the subject's location. The ISA task was easier because it required only identification of the object to elicit a behavioral response. When appropriate, the ISA task was reversed to allow comparison betwecn the neuron responses to the same stimulus objects with the same behavioral response contingency in the two tasks.

Place-dependent conditional stimulus-response association (PCA) task. The cab was always placed in one of the four corners of the experimental field (place I, II, III, or IV), and it was moved by the experimenter in a pseudorandom order after each trial. In each trial the order was as follows: arousal tone, presentation of the outside view (place phase), presentation of one of two familiar objects, which were different colored blocks (object phase) in place I or II. In place I, a red block required the monkey to release the lever (go trial), and a blue block required holding the lever (no-go trial) to obtain a few drops of juice (symmetrical reinforcement). In place II, the behavioral responses indicated by the two objects were reversed; a red block required holding the lever (no-go trial) and a blue block required release of the lever (go trial) to obtain a reward. There were thus four correct combinations of place, object, and behavior in the PCA task (place I-red-go, place Iblue-no-go, place II-red-no-go, place II-blue-go). In places III and IV, there was no task requirement, no reward, and no analysis. The use of the intervening positions without task performance was intended to diminish the subject's association of frequency or direction, or vestibular influence due to cab motion with the behavioral response required to perform the task. Trials occurred at a rate of one every $50-60 \mathrm{sec}$.

Each trial (Fig. 1C) began when the monkey pressed and held a response lever after a $30-40 \mathrm{sec}$ intertrial interval (ITI). After holding the lever 4-6 sec (control phase), a pure tone $(1700 \mathrm{~Hz}, 1 \mathrm{sec})$ to alert the monkey was presented. After a $1 \mathrm{sec}$ delay following the tone, the inside cab lamps were turned off for $3 \mathrm{sec}$ (place phase). During the place phase, the monkey could see outside of the cab through the half mirrored cab walls. The inside cab lamps were again turned on, and after another $1 \mathrm{sec}$ delay an object behind the half-mirrored shutter was illuminated for $1 \mathrm{sec}$ (object phase). When the object indicated go at that location (go trial), the monkey was required to release the response lever within $2 \mathrm{sec}$. If the monkey responded correctly, a reward of approximately $0.2 \mathrm{ml}$ of orange juice was presented for $2 \mathrm{sec}$ after another $1 \mathrm{sec}$ delay (a correct trial). If the monkey failed to respond correctly, a $620 \mathrm{~Hz}$ buzzer tone was presented and reward was withheld (an error trial). The time course of a no-go trial was similar, but the monkey was required to keep holding the lever for $5 \mathrm{sec}$. After holding the lever for $5 \mathrm{sec}$, the orange juice reward was presented for $2 \mathrm{sec}$ (a correct no-go trial). After the end of each trial the cab was moved to the next place during the $30-40 \mathrm{sec}$ ITI, during which the monkey could not see outside the cab, and the control phase of the next trial then began. Place-object combinations were chosen and tested in a pseudorandom, balanced fashion so that go and no-go trials each comprised half of the trials, but the same go or no-go response did not occur more than four times in succession.

Place-independent simple stimulus response association (ISA) task. To characterize the object responsive neurons recorded in the PCA task, most of them were also analyzed in the place-independent simple stimulus-response association (ISA) task and/or its reversal (reversed ISA).

In the ISA task, two pairs of familiar objects were associated with go/no-go responses the same as in the PCA task, but the red object always required go while the blue object always required no-go to obtain a reward in the ISA task (symmetrical reinforcement). The other pair included a black object for go and a white object for no-go. In the ISA task, the inner cab lamps were turned on throughout the trials so the monkey could not see outside of the cab to visually identify its location, so there was no place phase before the object phase; the time course was the same as that of the PCA task, except that there was no place phase $(3 \mathrm{sec})$ and no delay $(1 \mathrm{sec})$ between the place and object phase.

The object-behavioral response contingency in the ISA task was constant, so that the ISA task required simple association between the object and the behavioral response without the conditional structure of the PCA task. It should be noticed that this task does not involve any association between a stimulus and reinforcement, since both of the correct go and no-go trials are symmetrically reinforced. The ISA task and the reversed ISA task allowed comparison of neuronal responses with those in the PCA task, since the reversed ISA was equivalent to the PCA in position II, but without the place phase. 
A.

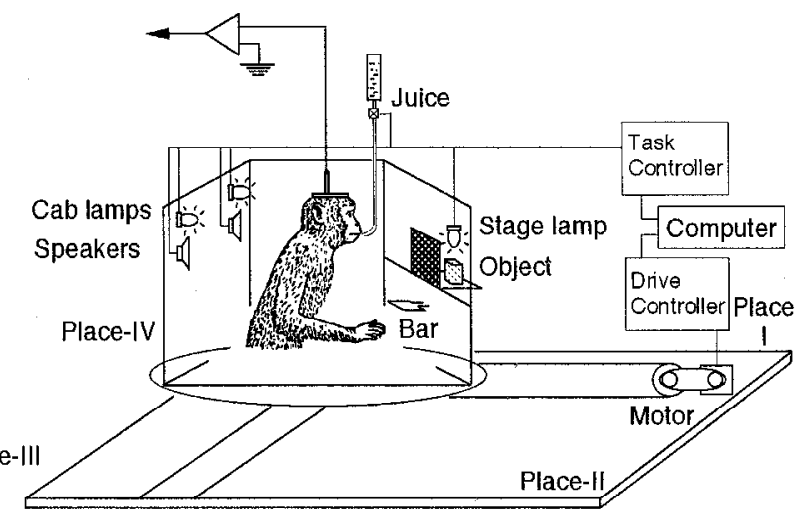

B.

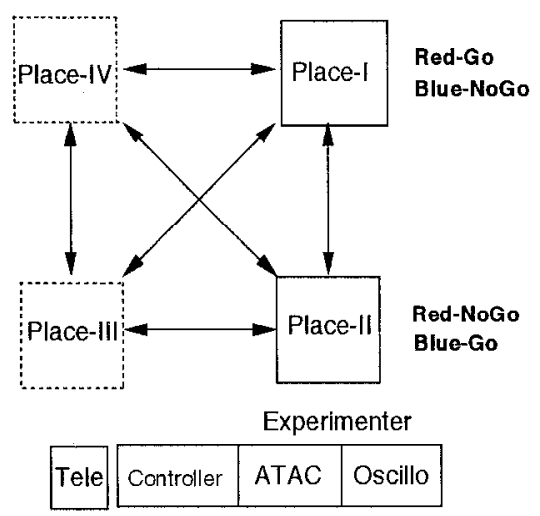

C. Place-dependent Conditional Stimulus-Response Association (PCA) task

a. Go

Bar-holding and bar-release

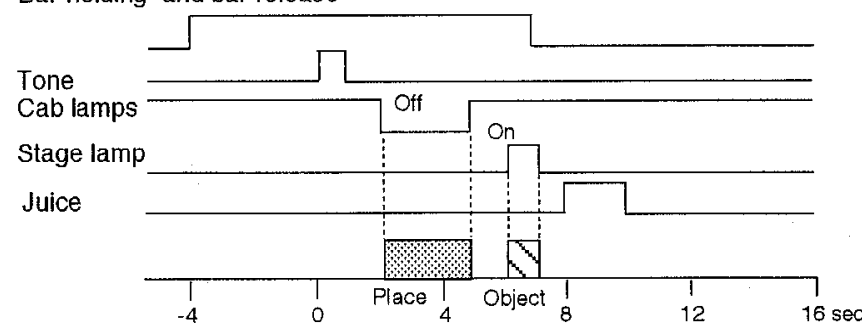

b. NoGo

Bar-holding and bar-release

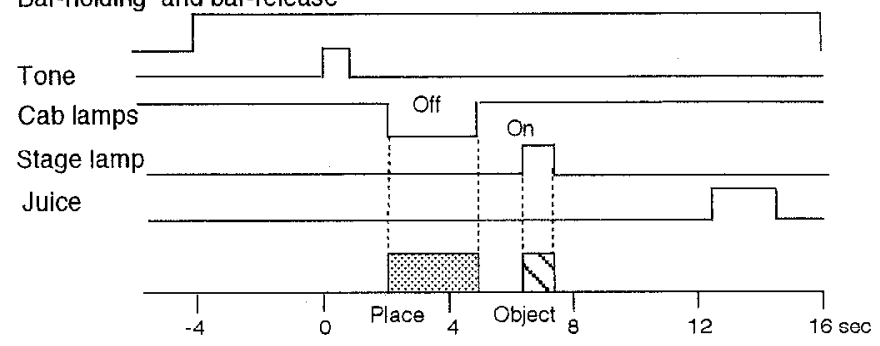

Figure 1. Schema of the experimental environment and paradigm. A, Movable monkey cab. Monkey sat in a chair in a cab $(0.7 \times 0.8 \times 0.85$ $\mathrm{m}$ high). Front, left, and right walls of the cab were half-mirrored. Rear wall, made of steel, was equipped with two symmetrically placed cab lamps and speakers. The upper half of the cab front wall contained a half-mirrored shutter $(15 \times 15 \mathrm{~cm})$ just above an operant bar. A front lamp behind the shutter illuminated an object in the bay. $B$. The entire apparatus was in a $5 \times 6 \mathrm{~m}$ shielded experimental room. The cab was moved to one of four places (place I, II, III, and $I V$ ) in a $2.5 \times 2.5 \mathrm{~m}$ field. The place-dependent conditional stimulus-response association task (PCA task) was imposed in places I and II. In place I, the red block indicated go behavior and the blue block, no-go. In place II, the behavioral response contingency was reversed. Thus, there were four correct combinations, that is, place I-red-go, place I-blue-no-go, place II-red-no-go, and place. II-blue-go, all of which were symmetrically reinforced. Places III and IV were intervening places with no task, no reward, and no recording. Tele, telemeter; Contr, controller; ATAC, microcomputer ATAC 3700; Oscillo, oscilloscope; PC98, microcomputer; Refr, refrigerator. Monkey always faced in direction of table and Refr. $C$, Time sequences of PCA task. During the $3 \mathrm{scc}$ the cab light was off, the monkey could see the room environment through half-mirrored walls (place phase). While the front lamp was on for $1 \mathrm{sec}$, a given object was visible behind the shutter (object phase). If the object indicated go behavior, the monkey was required to release the lever (go trial, $\mathrm{Ca}$ ); while no-go required holding the lever (nogo trial, $C b$ ). Details are in the text.

It should be noted that this ISA task is not categorized as the conditional spatial response task used by Rupniak and Gaffan (1987). The behavior required of the monkey in the IS $\Lambda$ task is only to release (go) or hold (no-go) the response lever. Therefore, approach or withdrawal behavior, which is required in the conditional spatial response task, is not involved in the ISA task. Thus, spatial influence on the behavioral response is controlled.

Training. A monkey was first trained in the ISA task and its reversal, which required about $1.3-2.7$ weeks for $90 \%$ proficiency. It was then trained in a modified version of the PCA task in which the intervening and no-task places (III and IV) were not used. In the next stage, it was trained in the proposed PCA task, which required about 3.9 months to reach $90 \%$ proficiency, and it was finally trained in all planned tasks (ISA and its reversal, and PCA) in succession (4.2 months to reach 93\% proficiency). After this, each monkey was overtrained for about 1.3 weeks with both the ISA, including its reversal, and PCA tasks.

It should be noted that in the initial part of the training the monkeys were trained with the windows in the side panels open. After the monkeys could perform the task correctly more than $90 \%$ of the time, the windows were closed and the monkey were retrained, until the monkeys could perform the task correctly more than $90 \%$ of the time. Therefore, the monkeys could see outside the cab during movement of the cab in the initial training phase.

Surgery. After completion of this training period, a head-restraining device, a U-shaped aluminum plate was attached to the skull under asepsis and sodium pentobarbital anesthesia ( $35 \mathrm{mg} / \mathrm{kg}, \mathrm{i} . \mathrm{m}$.). The de- vice was anchored with dental acrylic to stainless steel bolts inserted in keyhole slots in the skull. During the surgery, heart and respiratory functions, and rectal temperature were monitored on a polygraph system (Nihon Kohden), and rectal temperature was controlled at $37 \pm 0.5^{\circ} \mathrm{C}$ by a blanket heater. Antibiotics were administrated topically and systenicully for a week to protect against infection. Two weeks after surgery, the animals were retrained. Performance criteria for the PCA and ISA tasks were again attained in about 1.5 weeks. All monkeys were treated in strict compliance with the policy of the National Institutes of Health on the care of humans and laboratory animals. The amount of time the monkey was restrained in any one daily session was usually within 4 hr a day.

Recording. A glass-insulated tungsten microelectrode (1-2 $\mathrm{M} \Omega$ at $1000 \mathrm{~Hz}$.) was sterentaxically inserted vertically into the $\mathrm{HF}$ stepwise by a pulse motor-driven manipulator (SM-21, Narishige). Extracellular activity was passed through a high input impedance, preamplifier made of a dual channel field-effect transistor (2SK389, Toshiba Electric), amplified by a main amplifier, transmitted by a telemeter system (Nihon Kohden), monitored on an oscilloscope, and recorded on magnetic tape (A-614, Sony Magnescale). The neuronal activity was bandpass filtered in both the telemetry system, with $3 \mathrm{~dB}$ cutoff in $100 \mathrm{~Hz}$ and $1 \mathrm{kHz}$, and at the main amplifier, with $18 \mathrm{~dB}$ cutoff at $600 \mathrm{~Hz}$ and $6 \mathrm{kHz}$. Neuronal activity was counted by a time window discriminator (EN$611 \mathrm{~J}$, Nihon Kohden). Only neuronal activities with signal to noise greater than 2.5:1.0 were used. To assess the accuracy of neuronal spike isolation, the analog signal, the trigger levels, and the output of the 
discriminator were monitored continuously on an oscilloscope during analysis. The spikes and lever presses were recorded by an on-line minicomputer (ATAC 3700, Nihon Kohden), and displayed as peristimulus time histograms with $100 \mathrm{msec}$ bins by another computer (PC9801, NEC.)

Protocol for testing HF neurons. In almost all recording sessions, the monkeys performed the PCA and ISA tasks $95 \%$ correct on average. In the reversal of the ISA task, the monkey attained more than $95 \%$ correct performance within 40 trials. Usually, task performance in the early sessions had already attained the level of $93 \%$, and in the later sessions it gradually increased to about $97 \%$. All of the data analyzed for neuronal activity relations are based on recordings during correct trials.

When a spontaneously active neuron was located, it was first tested in the PCA task until at least one set of neuronal responses in all four combinations of place, object, and behavior were recorded. The arbitrary criterion required a minimum of seven trials of each combination with no error. Usually, more than 10 trials of each combination were carried out to permit estimation of the responsiveness of the neuron. Typically, the ISA task with two object pairs was then introduced, using the black/white pair first, and then the red/blue pair, and recording these neuronal responses until a minimum of seven responses were recorded with no error. After an ISA task session, the PCA task results were confirmed. After this, when convenient, a reversed ISA task was introduced, which was followed again by the PCA task.

Analysis of individual data. Spontaneous activity of each trial was defined as the mean activity in the $2 \mathrm{sec}$ of the control phase that ended $500 \mathrm{msec}$ before the alarm tone. Since, in some neurons, mean spontaneous activity of the same neuron was different in the PCA and ISA tasks, the average spontaneous activity of all trials was calculated separately for the two tasks. Place phase activity of each trial was defined as the mean activity in the first second of the place phase. During this period, EOG indicated that neuronal activity was not correlated with eye movement. Object phase activity of each trial was the mean activity in the first $800 \mathrm{msec}$ of the object phase. This time window was selected becausc it was considered to be comparable to the mean reaction time in a correct go trial. In this period, EOG confirmed that the eye movements of the monkey was not related to the recorded neuronal activity.

Neuronal activity during the place and object phases was analyzed in terms of four place-object-behavior combinations (see Place-dependent conditional stimulus-response association (PCA) task). Excitatory or inhibitory responses during the place and object phases were considered significant if a Student's $t$ test of the difference between the spontaneous activity and object phase activity or the place phase activity indicated $p<0.05$. Responses among four combinations were compared by one-way ANOVA, with significance levels at $p<0.05$. Each comparison of the responses between two possible pairs of four combinations were made by the Newman-Keuls method of multiple comparisons with significance at $p<0.05$.

Differential response index. To analyze population behavior of neu ronal responses in the object phase, differential response indices were introduced. The average magnitude of activity rate in response to a given combination is the mean of the object-phase activity rate for more than seven trials of that combination minus the average spontaneous rate of the neuron activity. If the average object-phase neuronal response rates are $R_{\mathrm{RG}}=\mathrm{red} / \mathrm{go}$ (at place I), $R_{\mathrm{BN}}=$ blue/no-go (at place I), $R_{\mathrm{RN}}=$ red/no-go (at place II), and $R_{\mathrm{BC}}=$ blue/go (at place II), the object-differential response index (OI), behavior-differential response index $(\mathrm{BI})$, and place-differential response index (PI) are defined as follows:

$$
\begin{aligned}
& \mathrm{OI}=\left|\left(R_{\mathrm{RG}}+R_{\mathrm{RN}}\right)-\left(R_{\mathrm{BN}}+R_{\mathrm{BG}}\right)\right| /\left|\left(R_{\mathrm{RG}}+R_{\mathrm{BN}}+R_{\mathrm{RN}}+R_{\mathrm{BG}}\right)\right| \\
& \mathrm{BI}=\left|\left(R_{\mathrm{RG}}+\mathrm{R}_{\mathrm{BG}}\right)-\left(R_{\mathrm{RN}}+R_{\mathrm{BN}}\right)\right| /\left|\left(R_{\mathrm{RG}}+R_{\mathrm{BN}}+R_{\mathrm{RN}}+R_{\mathrm{BG}}\right)\right| \\
& \mathrm{PI}=\left|\left(R_{\mathrm{RG}}+R_{\mathrm{BN}}\right)-\left(R_{\mathrm{RN}}+R_{\mathrm{BG}}\right)\right| /\left|\left(R_{\mathrm{RG}}+R_{\mathrm{BN}}+R_{\mathrm{RN}}+R_{\mathrm{BG}}\right)\right|
\end{aligned}
$$

Thus, OI reflects differences in the rates of neuronal responses in the object phase, in terms of object color, red or blue; BI reflects behavioral responses, go or no-go; and PI reflects the subject's location, place I or II.

For each of these three indices, a higher value, near 1 , indicates a higher differential response, and a lower value, near 0 , indicates a lower magnitude of differential response.

Task specificity index. To compare neuronal responses in the object phase between the PCA task and the ISA task, including its reversal, task specificity index (TSI) was introduced. TSI is defined as follows:

$$
\mathrm{TSI}=(|P|-|S|) /(|P|+|S|),
$$

where $P=$ the largest average response magnitude during the object phase among the four combinations of the PCA task; $S=$ the largest average response magnitude during the object phase among the available combinations in the ISA task.

The available combinations used for $S$ included the combination used to calculate $P$. Thus, TSI reflects the task specificity of a neuron. For example, if a neuron responded more strongly to a correct combination in the PCA task than in the ISA task, the TSI will be nearer 1; and if the strength of the response is similar in both tasks, the TSI will be nearer 0 . The task specificity of the responses of each neuron was based on the following arbitrary criterion: if the absolute value of TSI was smaller than 0.33 , the neuron responded similarly in the different tasks, and if TSI exceeds 0.33 , the neuron responded more strongly in the PCA task than in the ISA task. A TSI value of 0.33 means that $P$ equals $2 S$.

Histology. After the last recording session, several small marking lesions were made in the HF by passing $20-30 \mu \mathrm{A}$ of anodal current for $40 \mathrm{sec}$ through an electrode placed stereotaxically and monitored by $x$-ray. After that, each animal was deeply anesthetized with an overdose of sodium pentobarbital $(50 \mathrm{mg} / \mathrm{kg}$, i.m. $)$ and perfused transcardially with $0.9 \%$ saline followed by $10 \%$ buffered formalin. The brains were removed and cut into $50 \mu \mathrm{m}$ sections through the HF. Sections were stained with cresyl violet, and sites of electrical lesions were determined microscopically. The location of each recording site was then calculated by comparing the stereotaxic coordinates of the recording sites with those of the lesions. The positions of the HF and of the recording electrodes were checked by x-ray photography during the experiments, and these photographs were compared with those of the marking electrodes to verify the calculated recording sites.

\section{Results}

The activity of 329 neurons was recorded from the HF in two monkeys while they performed the PCA task. Of these, 88 (26.8\%) responded during the object phase in the PCA task and satisfied the criterion defined under Protocol for testing HF neuron in Materials and Methods. Of these 88, 49 (14.9\%) also responded during the place phase (both-phase neurons), and 39 (11.9\%) responded exclusively during the object phase (objectphase neurons). These neurons were classified according to their responsiveness in the PCA task. The both-phase neurons were classified into three subgroups; specific-combination, behaviordifferential, and nondifferential. The object-phase neurons were also classified into three subgroups: specific-combination, object-differential, and nondifferential.

\section{Both-phase neurons}

Specific-combination neurons. Of the 49 both-phase neurons, 8 ( $2.4 \% ; 8$ excited, 0 inhibited) responded significantly more strongly during the object phase in one specific combination of object, place, and required behavior in the PCA task than in the other three combinations (specific-combination both-phase neurons). Another characteristic of this type of neuron was their differential response to outside views during the place phase. A typical example of this type of neuron is shown in Figure 2. The neuron responded during the object phase, to the specific combination of the red block, place II, and no-go (Fig. $2 A a-d, f$ ); OI $=0.288, \mathrm{BI}=0.410, \mathrm{PI}=0.602$. It also responded more strongly to the outside view from place II than from place I (Fig. $2 \mathrm{Aa}-$ $e$ ). In the reversed ISA task, this neuron did not respond to the combination of red/no-go (Fig. 2C,D), although the object-behavioral response contingency was the same as in the PCA task $(\mathrm{TSI}=0.813)$. This indicates that the selective response to the combination of red object and no-go response in the PCA task is further constrained by the subject's location upon which the object-behavioral response contingency was conditional. Thus, this neuron responded to the conditional association of object, 


\section{A PCA task} a Place I Red (Go)

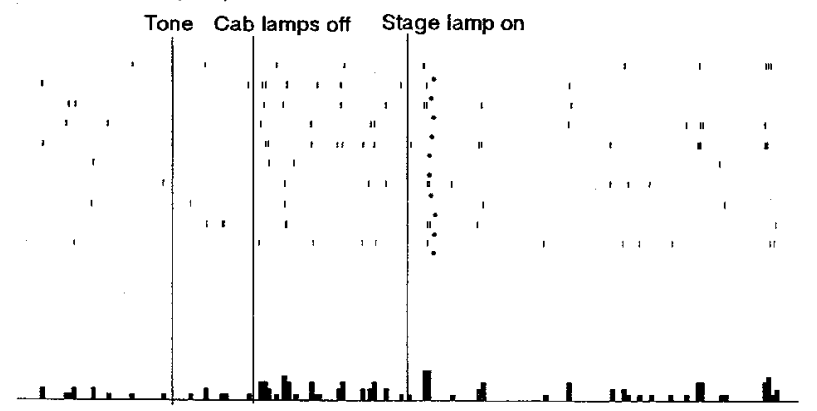

b Place I Blue (Nogo)

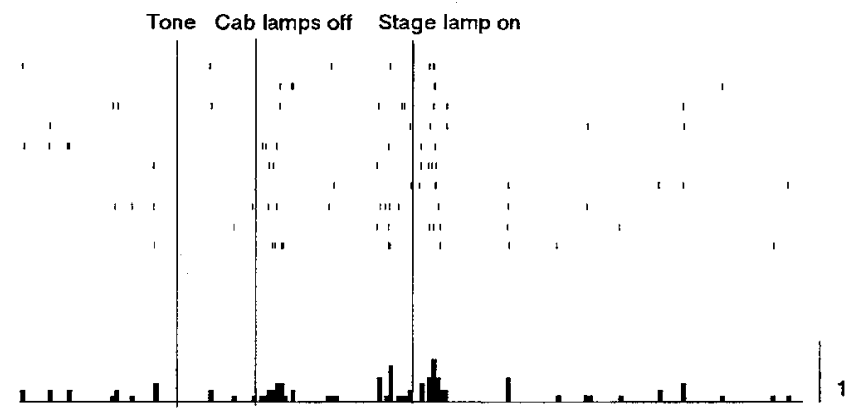

$1 \mathrm{sec}$

d Place II Blue (Go)

1 sec

c Place II Red (Nogo)

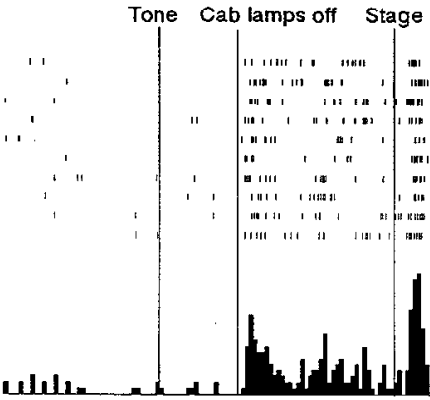

ule.
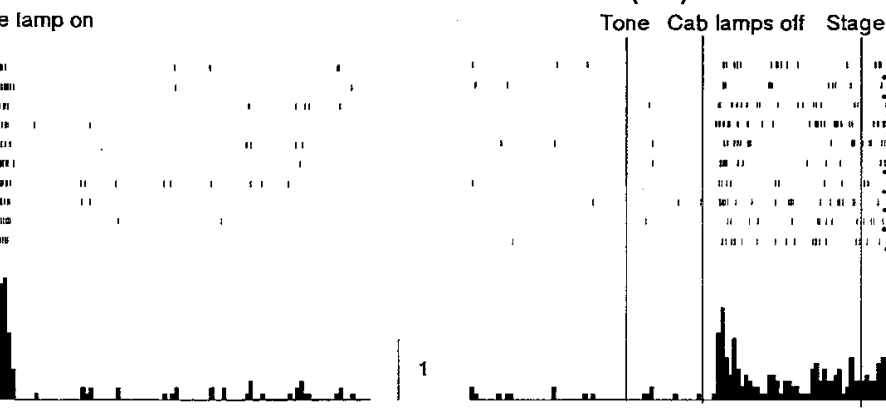

$1 \mathrm{sec}$

f Object phase

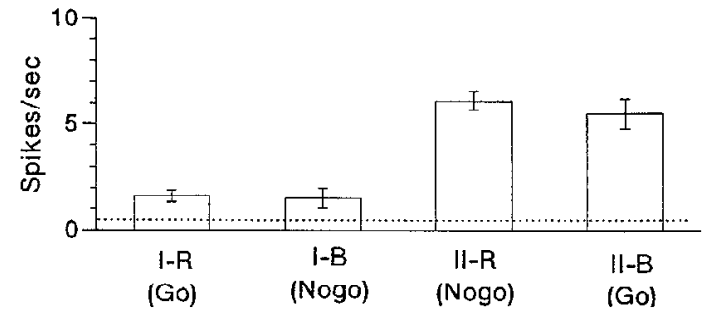

B ISA task

a $\operatorname{Red}(G o)$

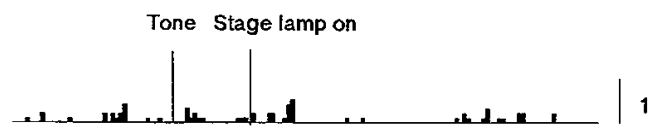

b Blue (Nogo)

$\overline{\text { isec }}$

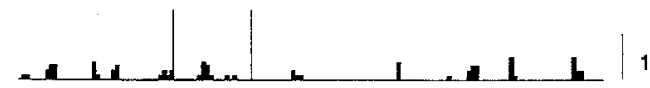

c Black (Go)

$\overline{\text { Isec }}$

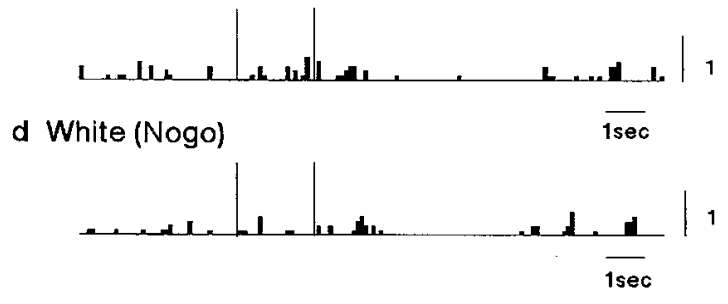

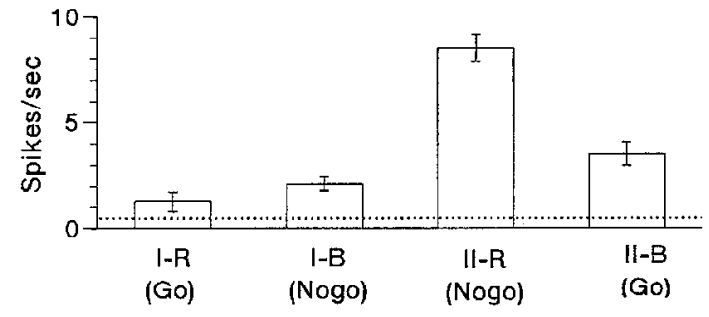

C Reversed ISA task

a Red (Nogo)

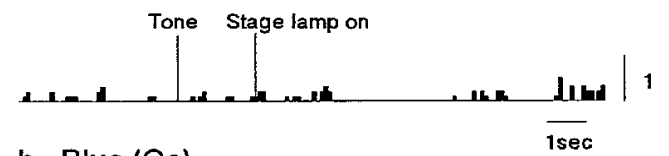

b Blue (Go)
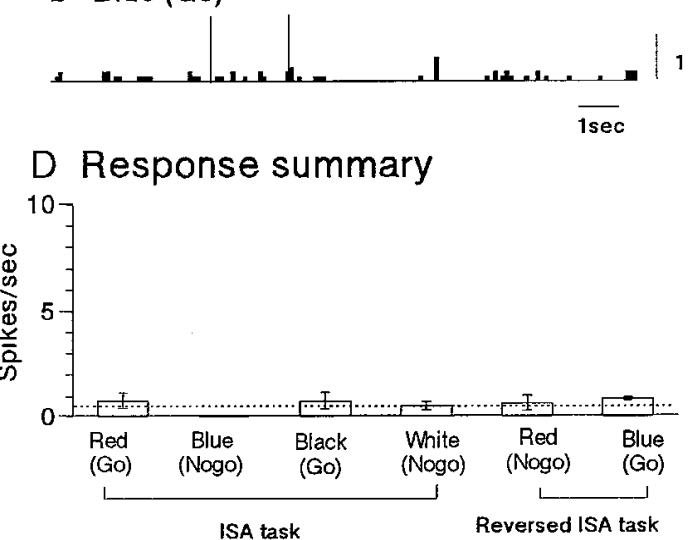

Figure 2. Responses of a typical specific-combination both-phase neuron. A, Neuronal activity in the PCA task. a-d, Rastergrams (upper) and cumulative $100 \mathrm{msec}$ bin, $20 \mathrm{sec}, 10$ trial histogram (lower) of neuronal activity during trials of each place-object-behavioral response combination. Dots under each raster of go trials correspond to lever release. $e$ and $f$, Histograms of place phase activity $(e)$ and objcct phase activity $(f)$ for each combination. Dashed lines correspond to spontaneous neuronal activity during the task (see Analysis of individual data in Materials and Methods). 
behavior, and subject's location. Also, this neuron did not respond to any object in the original ISA task (Fig. $2 B, D$ ).

Of eight both-phase specific combination neurons, five had memory-related activity during a $1 \mathrm{sec}$ delay period between the place and the object phases, as was reported previously (O'Keefe and Speakman, 1987). In the case of the neuron shown in Figure 2, the neuronal responses in place II continued into the delay period $(A c, d)$. The average activity during the $1 \mathrm{sec}$ delay period following presentation of place II was $3.2 \pm 0.4$ spikes/sec, while that following presentation of place I was 1.2 $\pm 0.2 \mathrm{spikes} / \mathrm{sec}$. The difference in neuronal activity during the delay period based on the preceding place phase was statistically significant ( $p<0.01$, Student's $t$ test). However, the responses during the object phase in the specific combination in which a given both-phase specific combination neuron had the largest responses were not ascribed to memory-related activity following the place phase. The responses during the object phase in that specific combination were significantly larger than those during the delay period ( $p<0.01$, paired $t$ test).

Another characteristic of the specific-combination both-phase neuron was that the location where the place-phase response occurred was significantly correlated to the location where the object-phase response occurred, as depicted in Figure 2. The activity in the place phase at the location where the object-phase responses occurred was significantly greater than that at the location where object-phase responses did not occur $(p<0.01$, paired $t$ test). But this was not true of the other both-phase neurons such as the behavior-differential both-phase and the nondifferential both-phase neurons.

Behavior-differential neurons. Responses of 16 out of 49 both-phase neurons were correlated in the object phase $(4.9 \%$; 14 excited, 2 inhibited) to the behavior required, regardless of the kind of stimulation or the subject's location (behavior-differential neurons). Usually the responses of these neurons in the place phase were not significantly different. An example of a behavior-differential neuron is shown in Figure 3. This neuron had significantly stronger responses to the no-go stimulus in the object phase of the PCA task, regardless of the object or the subject's location (Fig. 3Aa-d,f); OI $=0.100, \mathrm{BI}=0.697$, and $\mathrm{PI}=0.089$. On the other hand, responses of this neuron in the place phase of the PCA task were not significantly different (Fig. $3 A a-e)$. This neuron also responded more strongly to the no-go stimulus in the object phase of the ISA task, regardless of the object (Fig. $3 B, D$ ). In the reversal version of the ISA task, this neuron responded differentially to the no-go stimulus after full acquisition, although the same stimulus objects were used (Fig. $3 C, D$ ). These responses were not specific to a task, because they were similar in both the PCA and the ISA tasks (TSI $=0.100$ ). Thus, neuronal activity of this neuron is differentially associated with the behavioral response contingency of the object, regardless of the object or the task.

Nondifferential neurons. Responses of 25 of the 49 bothphase neurons $(7.6 \%, 21$ excited, 4 inhibited) were not signifi- cantly different among the four combinations in both phases (nondifferential both-phase neurons). An example is shown in Figure 4 . This neuron responded nondifferentially in the place phase to outside views from locations I and II (Fig. 4Aa-e); and nondifferentially in the object phase to both objects, regardless of behavioral response contingency or the subject's location in the PCA task (Fig. 4Aa-d,f); $\mathrm{OI}=0.027, \mathrm{BI}=0.001, \mathrm{PI}=$ 0.070 . This neuron also responded nondifferentially to four objects in the ISA task (Fig. 4B) and responded similarly in both the PCA task and the ISA task (TSI $=0.136$ ). Thus, this neuron was not specific to the PCA task.

\section{Object-phase neurons}

Specific-combination neurons. Of the 39 object-phase neurons, $9(2.7 \%)$ responded to an object when it was in one of two places that indicated go or no-go; that is, its response depended on some specific combination of object, place, and required behavior in the PCA task (specific-combination object-phase neurons). Figure 5 shows an example of a typical specific-combination object-phase neuron. This neuron responded during the object phase, to the specific combination of the blue block, place II, and go response (Fig. $5 A a-d, f$ ); OI $=0.613, \mathrm{BI}=0.578$, PI $=0.415$, but did not respond during the place phase to the change of the outside view (Fig. $5 A a-e$ ). In the reversed ISA task, this neuron did not respond to the combination of blue/go (Fig. 5C,D), although the object-behavioral response contingency was the same as those in the PCA task (TSI $=0.922$ ). This indicates that, as in the case of the neuron in Figure 2, the selective neuronal response to the combination of blue object and go response in the PCA task was further constrained by the subject's location upon which the object-behavioral response contingency was conditional, so this neuron responded to the conditional association of an object, some required behavior and the subject's location. Also, this neuron did not respond to any object in the original ISA task (Fig. $5 B, D$ ).

Object-differential neurons. Of the 39 object-phase neurons, $12(3.6 \% ; 12$ excited, 0 inhibited) responded differentially in the object phase, regardless of the behavioral response that an object indicated, or of the subject's location (object-differential neurons). Figure 6 is an example of typical object-differential neurons. The neuron in Figure 6 had significant differential re sponses to a red block in the object phase of the PCA task, regardless of the behavioral response contingency or the subject's location (Fig. 6Aa-d,f); OI $=0.796, \mathrm{BI}=0.020$, and PI $=0.067$. This neuron had no significant responses in the place phase of the PCA task (Fig. 6Aa-e), and disappeared or diminished its response to the red object in the ISA task (Fig. $6 B, D$ ) as well as in the reversal version of the ISA task (Fig. 6C,D). Thus, these neuronal responses are specific to the PCA task, because they occurred specifically in the PCA and not in the ISA task (TSI $=0.730)$. These PCA task-specific object-differential responses were not constrained by the subject's location upon which the object-behavioral response contingency was

\section{$\leftarrow$}

This neuron responded in the place phase differentially to outside views of place II, and responded in the object phase differentially to one specific combination; place II-red block-no-go response. $\mathrm{OI}=0.288, \mathrm{BI}=0.410, \mathrm{PI}=0.602 . B$, Neuronal activity in the ISA task. $a-d$, Cumulative 100 msec bin, 10 trial histogram of neuronal activity during a trial of each object-behavioral response combination. $C$, Neuronal activity in reversal of the ISA task after full acquisition. $a$ and $b$, Cumulative $100 \mathrm{msec}$ bin, 10 trial histograms of neuronal activity during a trial of each object-behavioral response combination. $D$, Histogram of object phase activity in response to each object-behavioral response combination in the original and reversed ISA task. Dashed lines correspond to spontaneous neuronal activity during the lask. This neuron did not respond in the ISA task or its reversal; so it responded specifically in the PCA and not in the ISA task. TSI $=0.813$. 
A PCA task

a Place I Red (Go)

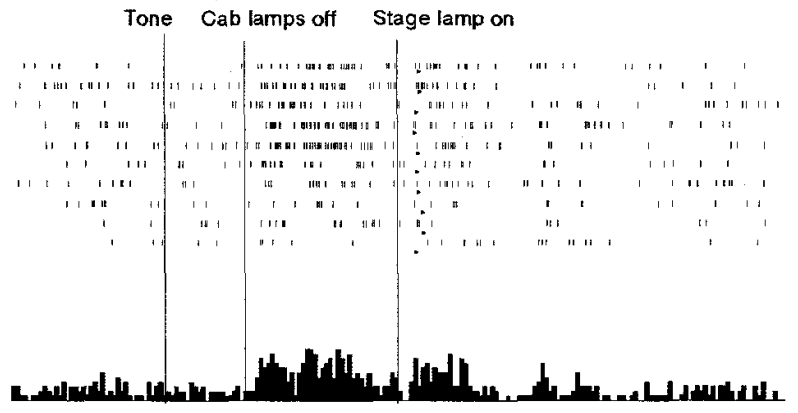

c Place II Red (Nogo)

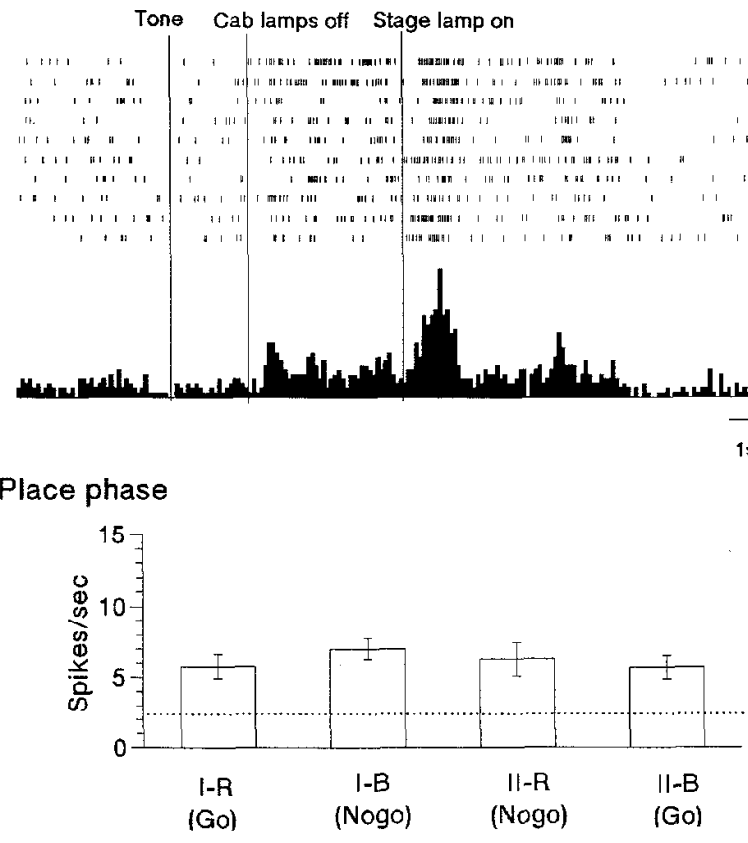

B ISA task

a $\operatorname{Red}(G 0)$ Tone Stage lamp on

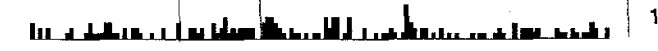

b Blue (Nogo)

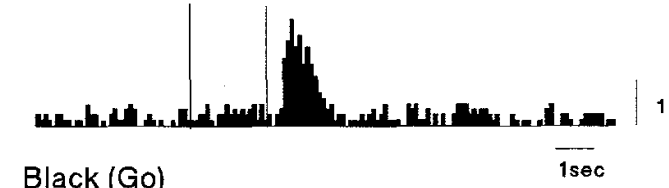

c Black (Go)

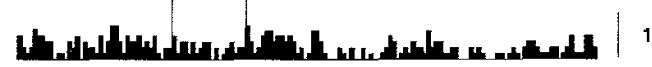

d White (Nogo)

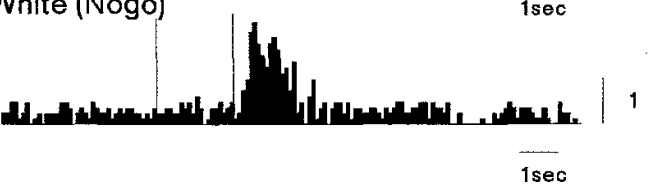

b Place I Blue (Nogo)

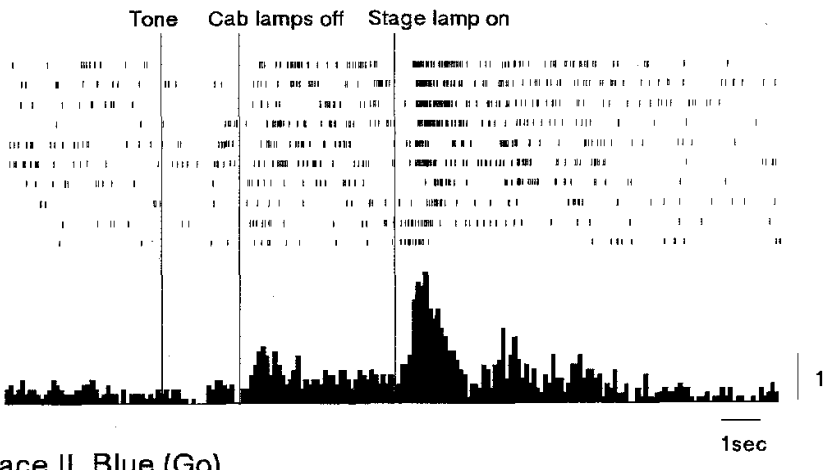

d Place II Blue (Go)

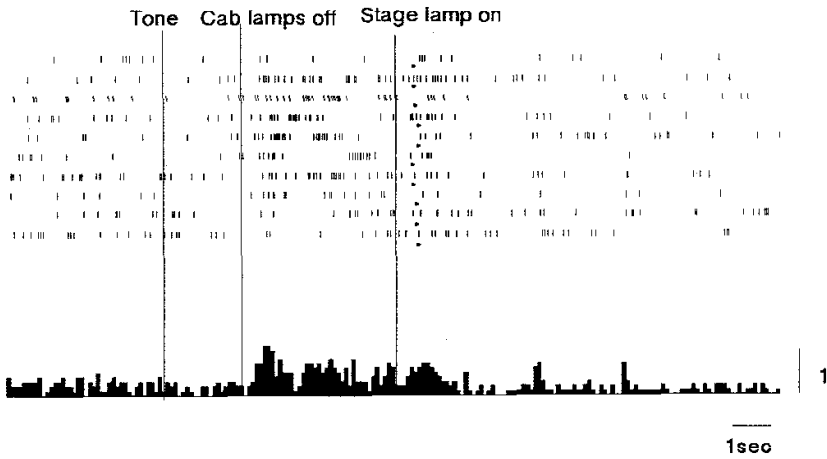

f Object phase

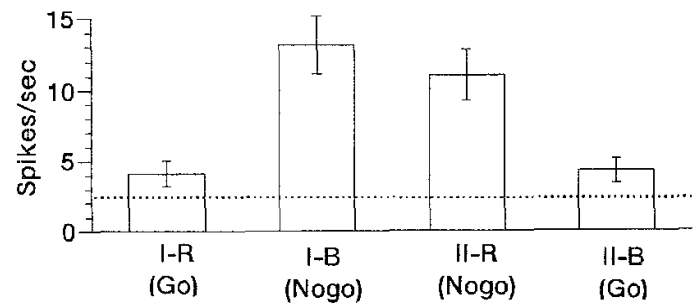

C Reversed ISA task

a Red (Nogo)

Tone Stage lamp on

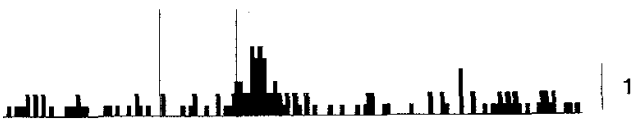

b Blue (Go)

1 sec

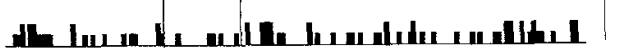

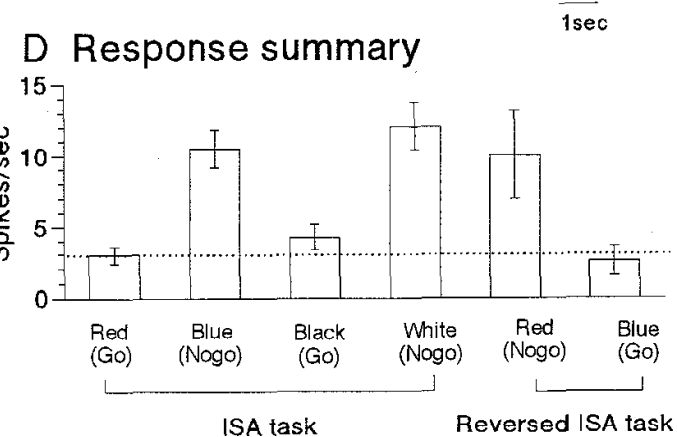


conditional, because neuronal responses to the same object occurred in both locations (Fig. 6Aa,c). This result indicates that the conditional structure of the PCA task rather than the subject's location, is what constrained the responses of this neuron.

Nondifferential neurons. Of the 39 object-phase neurons 18 $(5.5 \% ; 13$ excited, 5 inhibited) were nondifferential: they responded to all objects presented in the object phase (nondifferential object-phase neurons).

\section{Population data}

Differential response index. Figure $7 A$ is a three-dimensional plot of OI, BI, and PI of each recorded both-phase neuron. The groups of nondifferential $(\square)$, behavior-differential $(\triangle)$, and specific-combination neurons (O) are segregated. The population of specific-combination both-phase neurons was relatively high OI, BI, and PI; the centric point is $\mathrm{OI}=0.478, \mathrm{BI}=0.466$, $\mathrm{PI}=0.572$. Neurons in this group responded selectively to specific combinations of object, required behavior, and location in the PCA task. The population of behavior-differential neurons had a relatively high $\mathrm{BI}$, but other indices are low; the centric point is $\mathrm{OI}=0.049, \mathrm{BI}=0.704, \mathrm{PI}=0.063$. The population of nondifferential hoth-phase neurons had relatively low OI, $\mathrm{BI}$, and PI; the centric point is $\mathrm{OI}=0.057, \mathrm{BI}=0.051, \mathrm{PI}=0.037$.

Figure $7 B$ shows the object-phase neuron population. Among these neurons, the nondifferential $(\square)$, object-differential $(\nabla)$, and specific-combination (O) neurons were segregated. The population of specific-combination object-phase neurons had relatively high OI, BI, and PI; the centric point was $\mathrm{OI}=0.548$, $\mathrm{BI}=0.516, \mathrm{PI}=0.537$. These results were similar to those for specific-combination both-phase neurons. The population of object-differential neurons had relatively high OI, but the other indices were low; the centric point was $\mathrm{OI}=0.633, \mathrm{BI}=0.048$, $\mathrm{PI}=0.053$. Thus, these neuronal responses reflect object differences. The population of the nondifferential object-phase neurons had relatively low $\mathrm{OI}, \mathrm{BI}$, and $\mathrm{PI}$; the centric point was $\mathrm{OI}$ $=0.037, \mathrm{BI}=0.044, \mathrm{PI}=0.056$.

Segregation of the differential response indices of each neuron type in Figure 7 supports the choice of categories of neurons; nondifferential both-phase, behavior-differential, specific-combination both-phase, nondifferential object-phase, object-differential, and specific-combination object-phase. Table 1 summarizes the characteristics of the neuron types.

We also andyzed the neuronal responses of both types of specific-combination neurons in the object-phase, based on twoway ANOVA, in which one factor is the monkey's location, and the other is the stimulus for go versus no-go $(p<0.05)$. The results in Figure 7 showing that specific-combination neurons had high PI and BI imply that, in two-way ANOVA, interaction of place and behavior would be significant. Consistently, all specific-combination both-phase $(n=8)$ and specific-combination object-phase neurons $(n=9)$ had significant main effects and interactions $(p<0.05)$. Average \pm SEM of the percentage of the variance accounted for by the significant main effects (the subject's location, PL; and go or no-go, GN) and/or interactions $(\mathrm{PL} \times \mathrm{GN})$ obtained in the two-way ANOVA are, for the specific-combination both-phase, $\mathrm{PL}=27.5 \pm 4.8(\%), \mathrm{GN}=21.7$ $\pm 3.6(\%), \mathrm{PL} \times \mathrm{GN}=24.5 \pm 4.5(\%)$; specific-combination object-phase, $\mathrm{PL}=22.4 \pm 2.6(\%), \mathrm{GN}=20.1 \pm 2.9(\%)$, $\mathrm{PL} \times \mathrm{GN}=22.9 \pm 3.9(\%)$.

Task specificity index. Histograms of TSI distribution of each neuronal type of both-phase neuron are presented in Figure $8 \mathrm{~A}$. The distribution is bimodal. There is one group with relatively low values around TSI $=0$, which is composed mainly of nondifferential neurons and behavior-differential neurons. The other group with TSI $>0.6$, is composed mainly of specific-combination neurons. Based on our criteria, all specific-combination both-phase neurons (seven of seven tested, 100\%) either disappeared or distinctly diminished in their responses in the ISA task, but few behavior-differential neurons ( 1 of 14 tested, $7.1 \%$ ) and nondifferential both-phase neurons (1 of 19 tested, 5.3\%) distinctly changed their responses between the two tasks. This suggests that the population of specific-combination neurons is more specific to the PCA task. Among the three neuronal types, there was significant difference in TSI values (one-way ANOVA; $F(2,37)=35,385, \pm<0.0001)$. The post hoc test indicated that the mean value of the specific-combination neurons was significantly larger than those of the behavior-differential and nondifferential both-phase neurons (Newman-Keuls test, $p$ $<0.001$ ). This indicates that the specific-combination neurons responded more specifically than other neuron types in the PCA task.

Figure $8 B$ plots bimodal histograms of responses of the object-phase neuron population. The group around TSI $=0$ consisted mainly of nondifferential neurons, whereas the group with TSI $>0.33$, were mainly object-differential neurons and specific-combination neurons. Based on our criteria, many object-differential neurons ( 8 of 12 tested, $75 \%$ ) and most specific-combination object-phase neurons ( 7 of 8 tested, $87.5 \%$ ) distinctly diminished or eliminated their responses, whereas few nondifferential object-phase neurons ( 1 of 14 tested, $7.1 \%$ ) changed responses between the two tasks. As was true of the both-phase ncurons, there were significant differences in TSI values among the three neuronal types (one-way ANOVA; $F(2,31)=16.068$, $p<0.0001$ ). The post hoc test confirmed that the object-differential and the specific-combination neurons had significantly higher TSIs (Newman-Keuls test, $p<0.0001$ ), indicating that these neurons responded specifically in the PCA task, while nondifferential object-phase neurons were less specific.

These results, when extended to the whole population of specific-combination neurons and object-differential neurons, indicate two kinds of constraint on HF neuronal responses. One is the subject's location; high TSI of two types of specific-combination neurons indicates that they responded specifically or predominately in the PCA task, not in the ISA task, although the same stimuli with the same behavioral response contingency were utilized. It follows that these neuronal responses to an object with a specific behavioral response contingency were constrained by the subject's location upon which the object-behavioral response contingency was conditional, and thus, reflects conditional association of object, behavior, and subject's location.

Another constraint is the conditional structure of the task it-

Figure 3. Responses of a typical behavior-differential neuron. All figure descriptions are the same as Figure 2 except that $C a$ and $b$ are for five trials. $A$, This neuron responded in both place and object phases, nondifferentially in the place phase, and differentially to no-go in the object phase, regardless of the kind of object or the subject's location. OI $=0.100, \mathrm{BI}=0.697, \mathrm{PI}=0.089 . B-D$, This neuron also responded differentially in no-go trials, regardless of the kind of object, and responded similarly in the PCA and ISA tasks; TSI $=0.100$. 


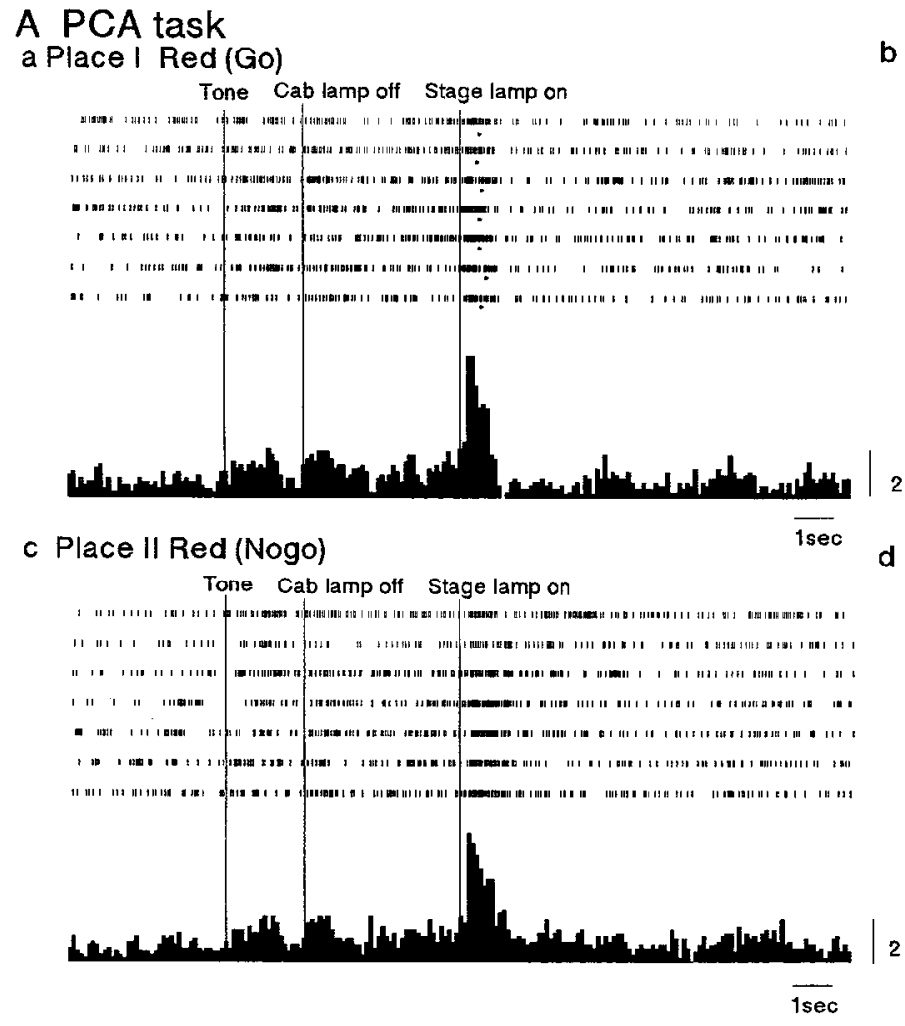

b Place I Blue (Nogo)

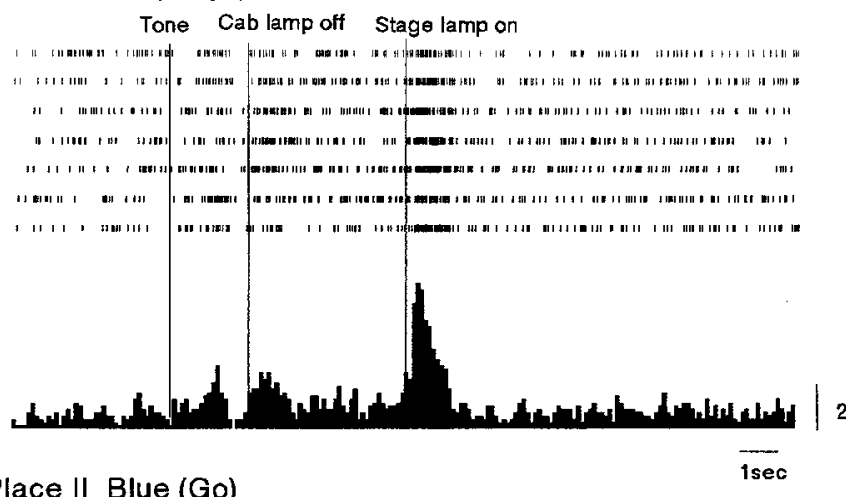

d Place II Blue (Go)

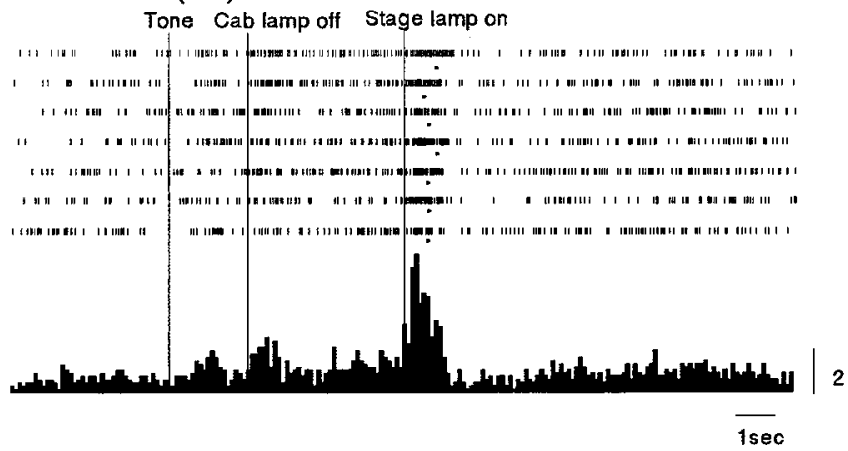

$f$ Object phase

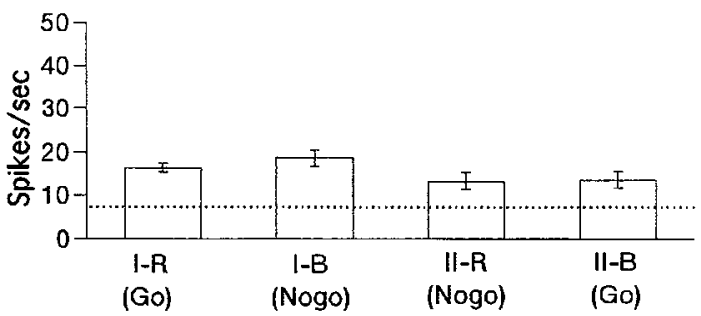

B ISA task

a $\operatorname{Black}(\mathrm{Go})$
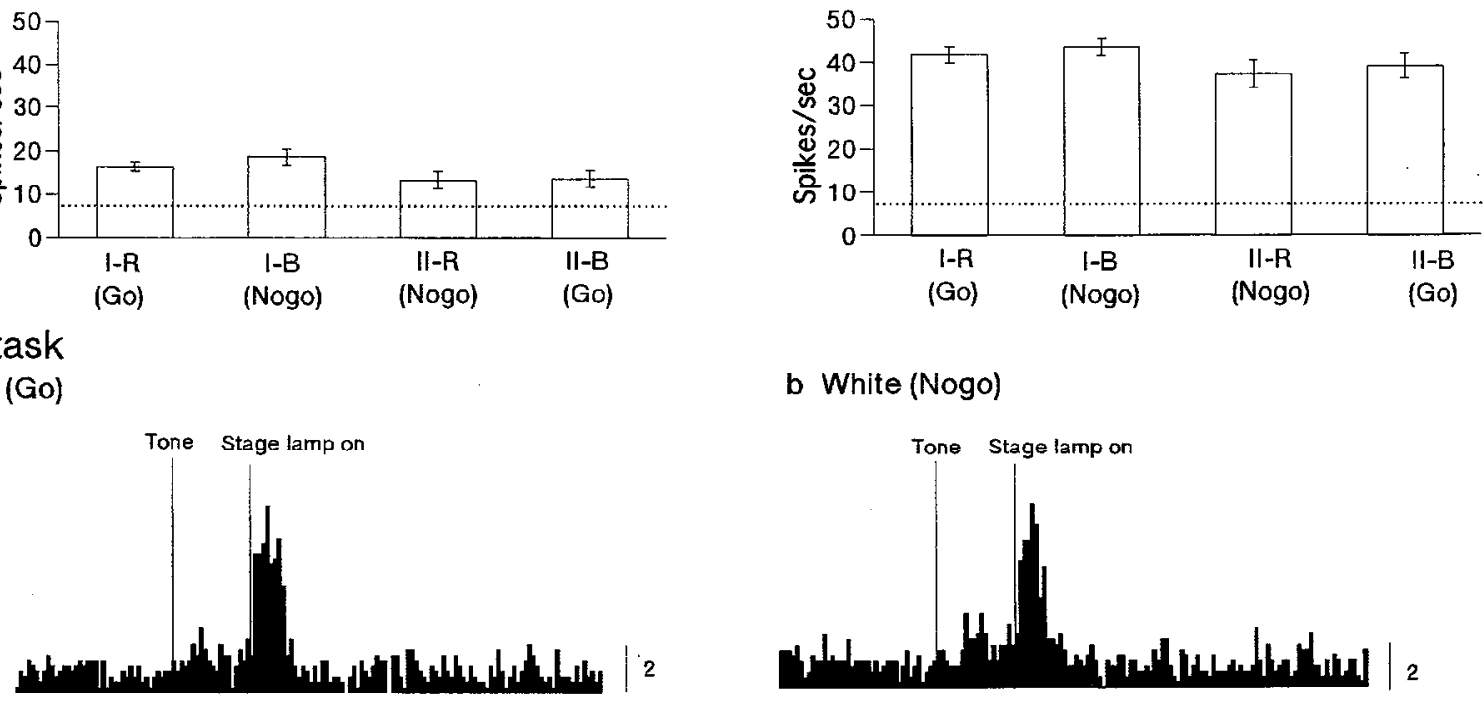

b White (Nogo)

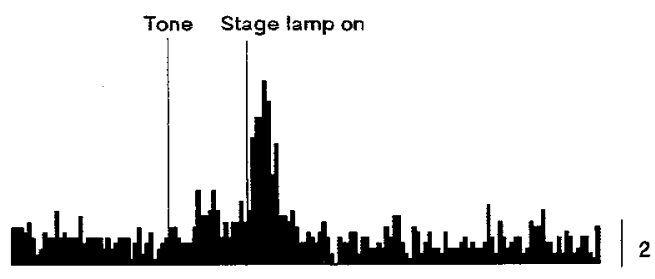

$\overline{1 \mathrm{sec}}$

c Response summary

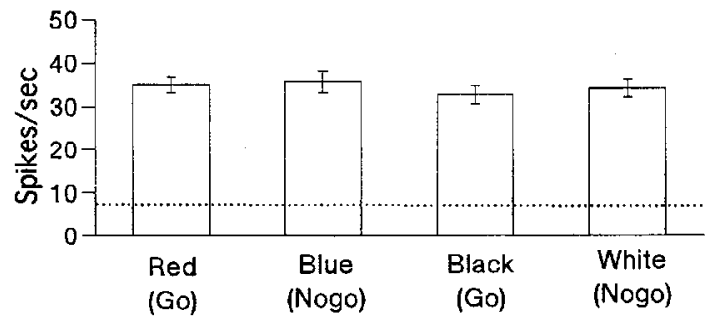

Figure 4. Responses of a typical nondifferential both-phase neuron. A, Neuronal activities in the PCA task. $a-d$, Rastergrams (upper) and cumulative $100 \mathrm{msec}$ bins, seven-trial histogram (lower) of neuronal activity during trials of each place-object-behavioral response combination. Dots under each raster of go trials correspond to lever release. $e$ and $f$. Histograms of place phase activity $(e)$ and object phase activity $(f)$ for each 
self; a high TSI for an object-differential neuron indicates that it responded specifically or predominately in the PCA task, which had a conditional structure, and not in the ISA task, which required simple object-hehavioral response association. This effect could not be attributed to place, because those neuronal responses occurred regardless of the subject's location (the average PI is 0.051 , while OI $=0.614$ ). We will discuss these constraints on $\mathrm{HF}$ neuron responses in more detail, later.

Average spontaneous activity. The mean value \pm SEM of the spontaneous activity of each type of neuronal population is shown in Table 1. The average spontaneous activity of the two types of nondifferential neurons (both-phase, $10.76 \pm 1.42$ spikes/sec; object-phase, $9.64 \pm 1.84$ spikes/sec) was high, but the average spontaneous activity of the behavior-differential neurons $(2.88 \pm 0.52 \mathrm{spikes} / \mathrm{sec})$, the object-differential neurons $(2.58 \pm 0.96$ spikes/sec $)$, and the two types of specific-combination neurons (both-phase, $3.58 \pm 1.23$ spikes/sec; objectphase, $3.01 \pm 0.94$ spikes/sec) were low. The average spontaneous activity ( $2.93 \pm 0.39$ spikes/sec) of the differential neurons (behavior-differential, object-differential, and two types of specific-combination neurons) was significantly lower than that $(10.24 \pm 1.21$ spikes $/ \mathrm{sec})$ of the two types of nondifferential neurons (two sample $t$ test with Welch's correction, $p<0.0001$ ).

Response latency. Distribution of the response latencies in the object phase of the PCA task are depicted in Figure $9 A$ for bothphase neurons and in Figure $9 B$ for object-phase neurons. The mean latency $(271.9 \pm 7.7 \mathrm{msec})$ of the differential neuron populations (behavior-differential, object-differential, and two types of specific-combination neurons) was significantly longer than that $(145.7 \pm 4.6 \mathrm{msec})$ of two types of nondifferential neuron populations (two sample $t$ test with Welch's correction, $p<$ 0.0001 ).

The average response latency of each neuronal type is described in Table 1 . There were significant differences in the latencies among six subgroups [one-way ANOVA; $F(5,74)=$ $62.578, p<0.0001]$. The post hoc analysis of the latencies of six subgroups indicated three groups with different latencies as follows (Newman-Keuls test, $p<0.001$ ). The response latencies of the two types of nondifferential neurons were short (bothphase, $141.9 \pm 5.0 \mathrm{msec}$; object-phase, $150.6 \pm 8.3 \mathrm{msec}$ ), but the response latencies of the object-differential neurons (293.3 $\pm 12.0 \mathrm{msec}$ ) and the two types of specific-combination neurons were relatively long (both-phase, $304.3 \pm 18.0 \mathrm{msec}$; objectphase, $297.5 \pm 11.6 \mathrm{msec}$ ). The response latency of the behavior-differential neuron was intermediate (228.8 $\pm 8.9 \mathrm{msec})$.

Locations of neuronal types. Figure 10 shows the locations of recorded neurons. Neurons were located throughout the hippocampus proper including the subfields CA1 $(n=82)$ and CA3 ( $n=100)$, the dentate gyrus $(n=95)$, the subicular complex ( $n=36$ ), and the parahippocampal gyrus $(n-16)$. Open squares $(\square)$ and filled squares $(\square)$ correspond to neurons that had, respectively, excitatory and inhibitory responses in the object phase of the PCA task. Dots ( $\boldsymbol{\square}$ ) are nonresponsive neurons. Figure 11 shows the location of each neuron type. The types as described are nondifferential both-phase $(\mathbb{D})$, behavior-differential $(\boldsymbol{\nabla})$, specific-combination both-phase $(\boldsymbol{O})$, nondifferential object-phase $(\square)$, object-differential $(\nabla)$, and specific-combination ohject-phase $(\bigcirc)$. They were diffusely distributed in the $\mathrm{HF}$ and the parahippocampal gyrus. There was little tendency to segregate in the dentate gyrus and the hippocampus proper CA1 and CA3, but they were scattered. In the subicular complex and the parahippocampal cortex, we found no specific-combination nor object differential neurons, although the sample examined was small. Table 2 summarizes the numbers, and locations of the neuron types.

\section{Discussion}

\section{Characteristics of the PCA task}

In the present study, most specific-combination and object-differential neurons fired specifically or predominately in the PCA than in the ISA task. In the PCA task, a subject's location was the condition upon which the object-bchavioral responsc association depended. We carefully designed the PCA and ISA tasks to match physical inputs to the sensory system (object presentation), and the required behavior was the same in both tasks. Therefore, the difference in sensitivity to the task could not be ascribed to differences in sensory stimulation nor to required motor responses. The difference between the two tasks was that in the PCA task the object-behavioral response contingency was conditional upon the subject's location, whereas in the ISA task, it was constant and independent of location.

To avoid vestibular cues in the PCA task, we introduced places III and IV with no task. Also, the cab was moved in random directions. We confirmed that behavior was affected by the outside view but not by the vestibular cues due to the movement. In one experiment, the cab lights were on throughout the $3 \mathrm{sec}$ place phase so the monkey could not see the outside view; it could thus not use visual sensory input to determine its location. In this control experiment, the monkey's correct performance in the PCA task fell to $52 \%$. This indicates that the monkeys did not rely on vestibular cues in the PCA task.

The monkey might, however, solve the PCA task by using the outside view as a complex visual stimulus, without using location cues. It is difficult to eliminate this possibility, since that would require the monkey to navigate itself around the experimental area, as reported in the studies of rat place cells (O'Keefe and Dostrovsky, 1971; McNaughton et al., 1983; Muller and Kubie, 1987). Data to date indicate that most of the responses of place-related neurons reported in the monkey have depended on external visual cues (Ono et al., 1993a,b). It was also reported that transection of the monkey fornix caused a deficit in conditional discrimination learning based on the room view (Gaffan and Harrison, 1989). This deficit appeared only when the salient objects in a view were the same, but the spatial relation between them were different. In the present study, the salient objects in the outside view during the place phase were constant. Spatial information processing to code a subject's location, or the outside view is important for resolving a PCA task.

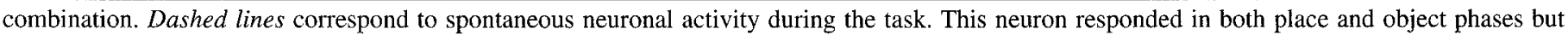

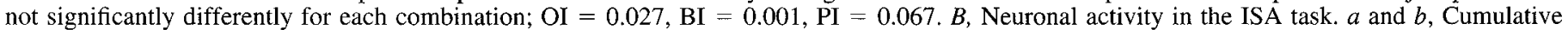

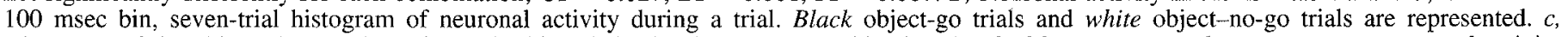

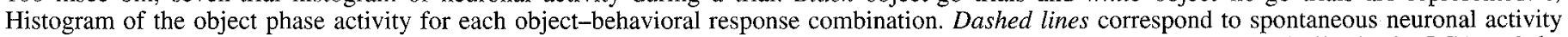

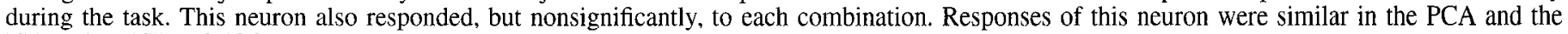
ISA tasks; TSI $=0.136$. 


\section{A PCA task} a Place I Red (Go)

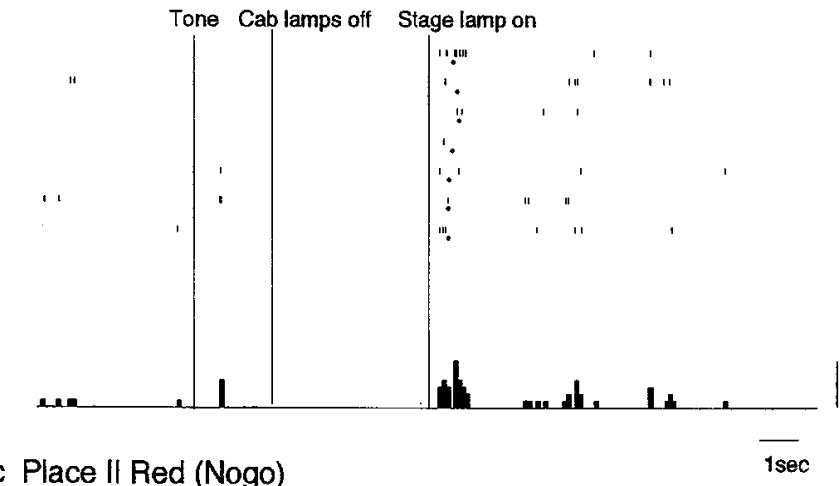

c Place II Red (Nogo)

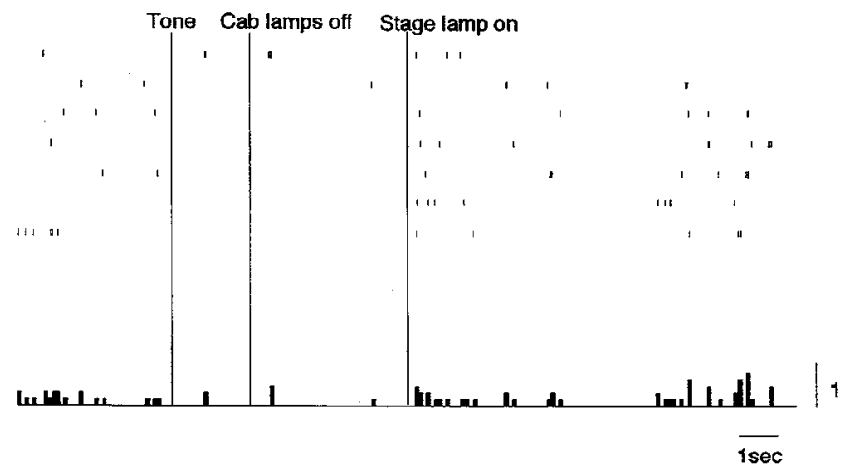

e Place phase

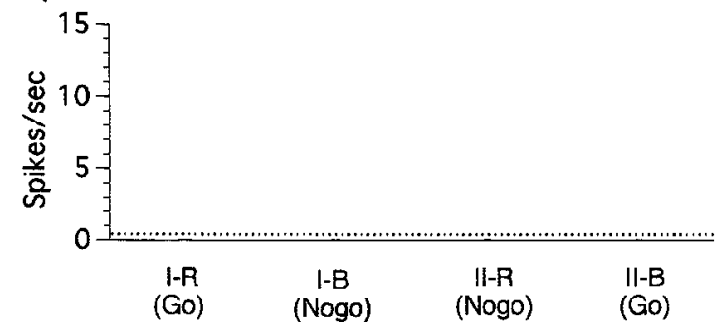

\section{B ISA task}

a $\operatorname{Red}(\mathrm{Go})$

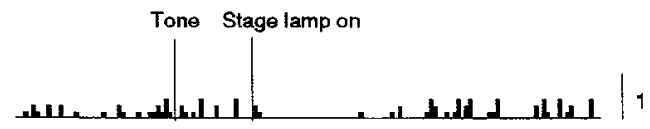

b Blue (Nogo)
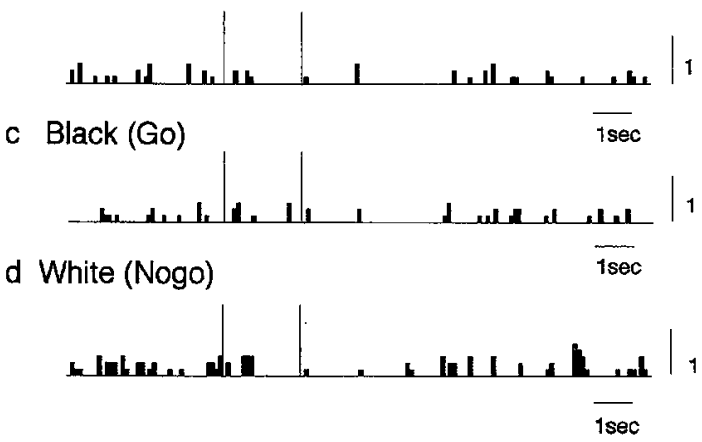

b Place I Blue (Nogo)

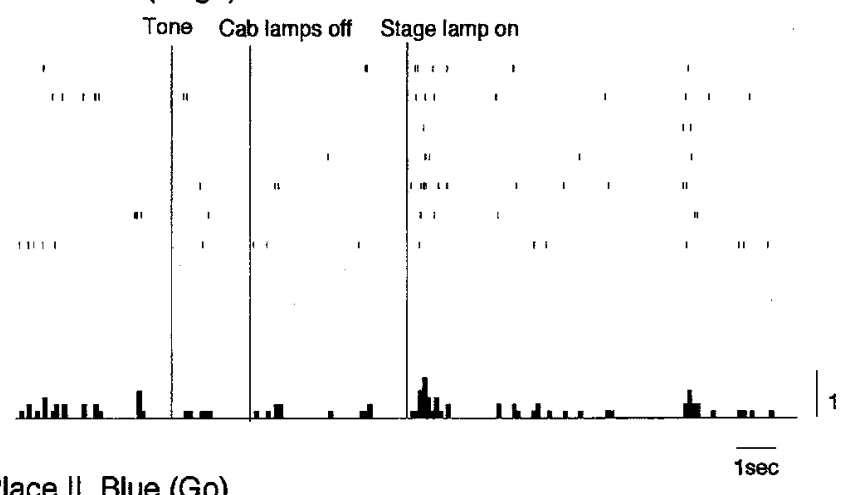

d Place II Blue (Go)

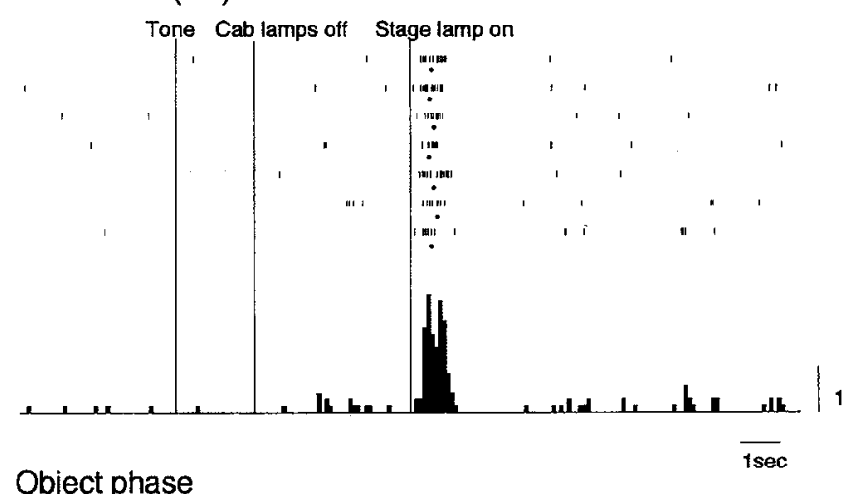

f Object phase

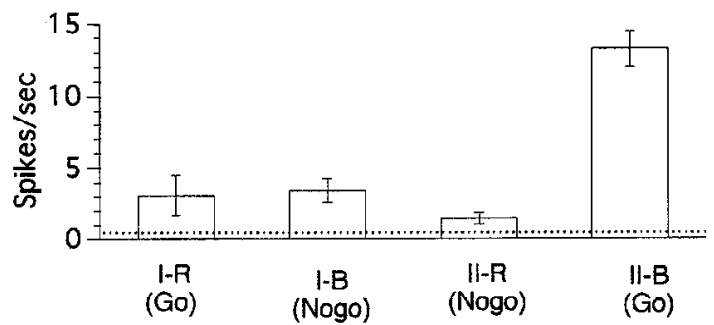

C Reversed ISA task

a $\operatorname{Red}($ Nogo)

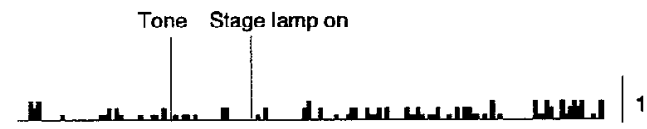

b Blue (Go)

$\overline{1 s e c}$

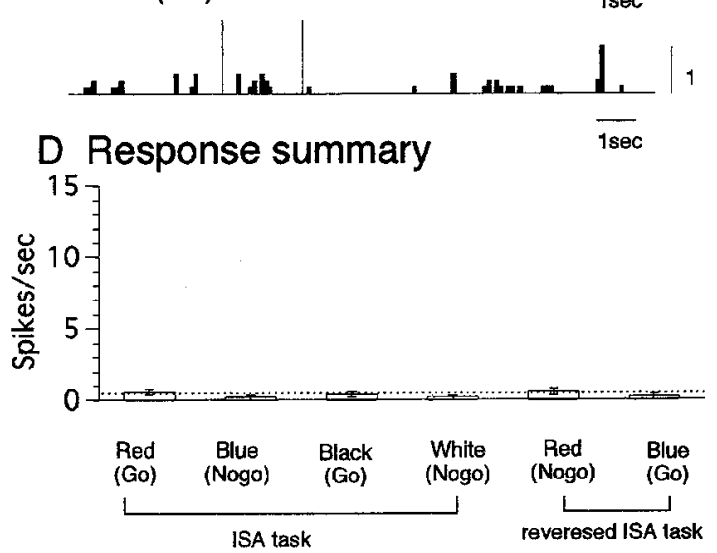

Figure 5. Responses of a typical specific-combination object-phase neuron. All figure descriptions are the same as for Figure 2, except that all data are for seven trials. $A$, This neuron did not respond in the place phase, but responded differentially in the object phase to one specific combination; place II-blue block-go response. $\mathrm{OI}=0.613, \mathrm{BI}=0.578, \mathrm{PI}-0.415 . B-D$, This neuron disappeared or diminished its response to the red block in the ISA task or its reversal, so it responded specifically in the PCA but not in the ISA task. TSI $=0.922$. 
A PCA task

a Place I Red (Go)

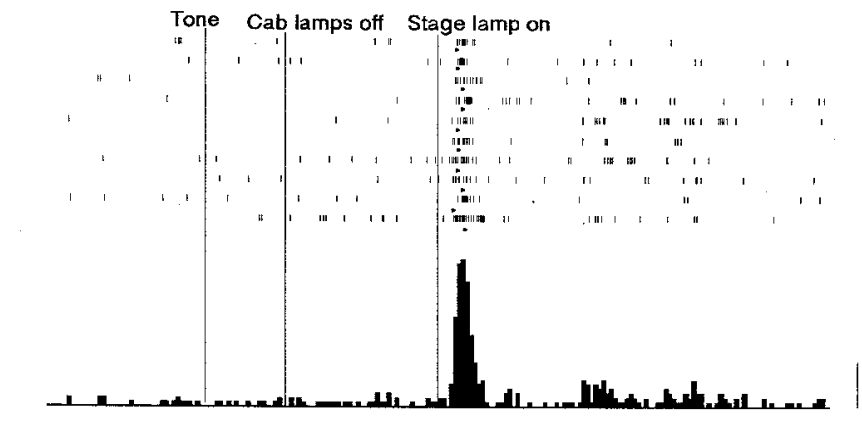

c Place II Red (Nogo)

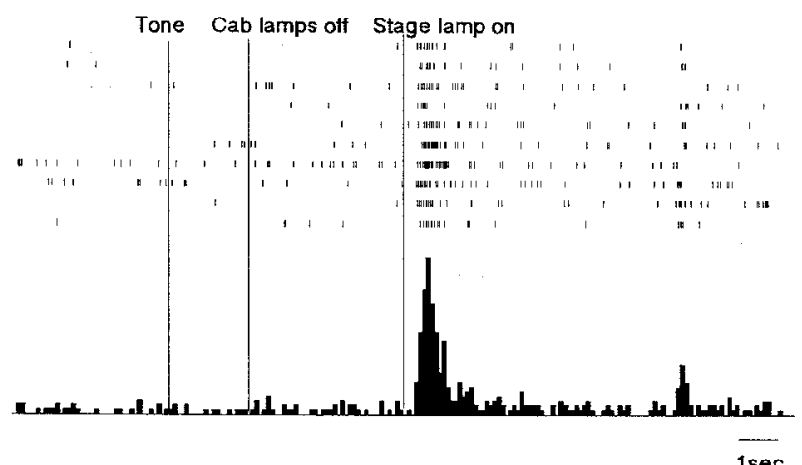

e Place phase

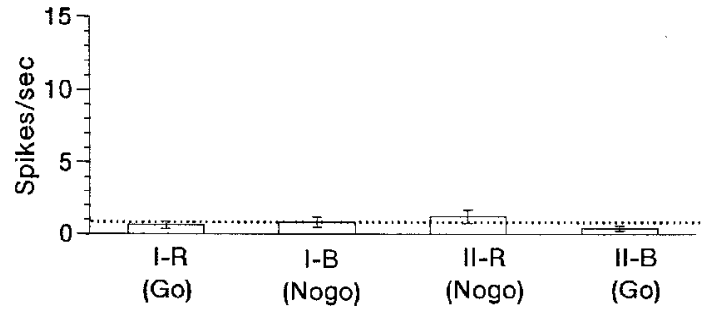

B ISA task

a $\operatorname{Red}(G o)$

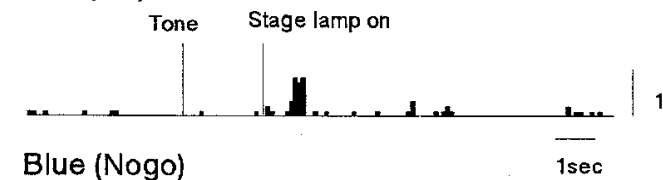

b Blue (Nogo)

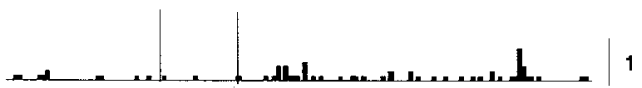

c Black (Go)

1. I

$\overline{1 s e c}$

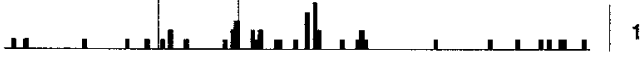

d White (Nogo)

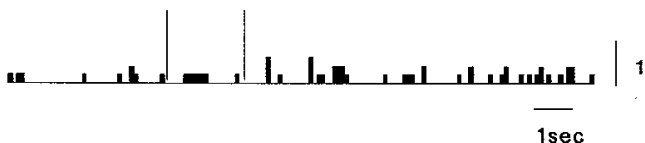

b Place I Blue (Nogo)

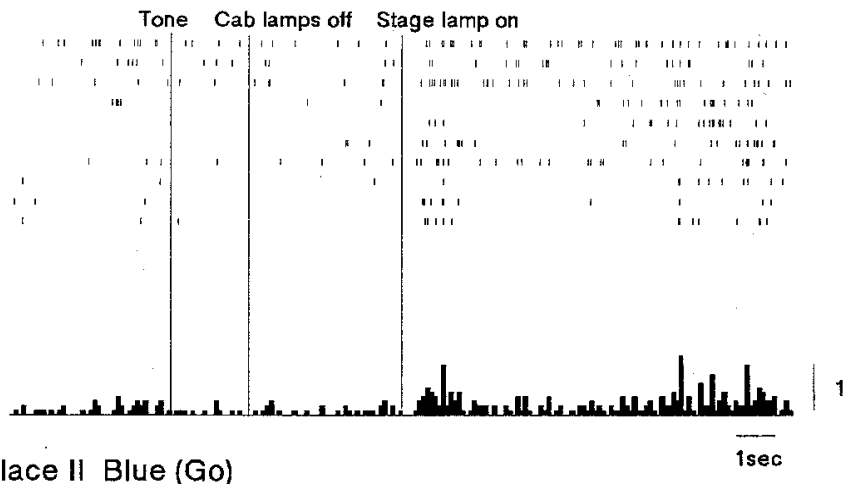

d Place II Blue (Go)

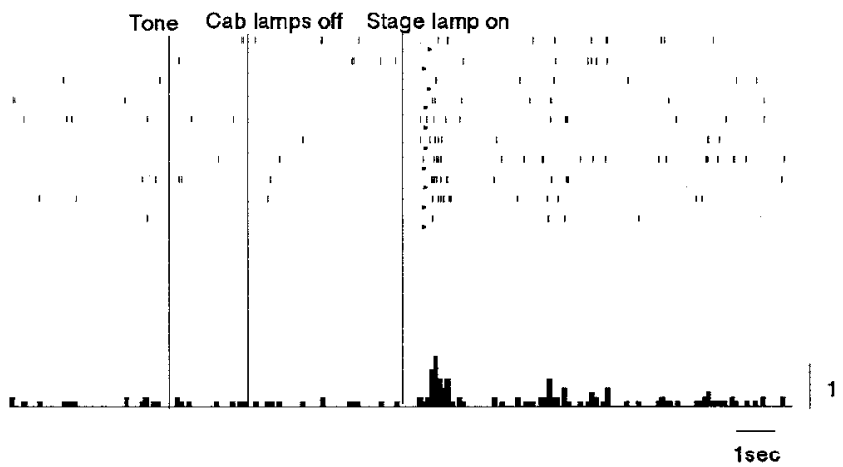

f Object phase

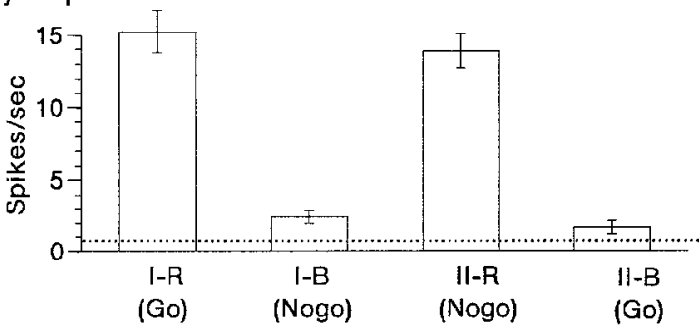

C Reversed ISA task

a Red (Nogo)

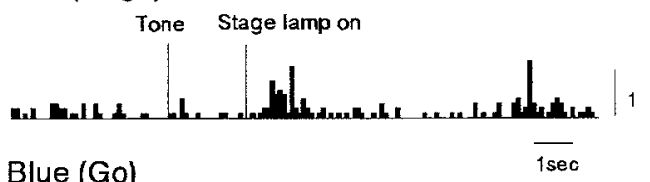

b Blue (Go)

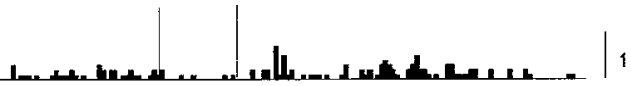

D Response summary

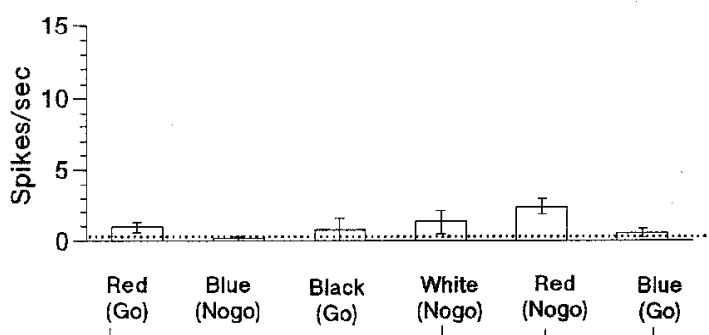

ISA task

Reversed ISA task

Figure 6. Responses of a typical object-differential neuron. All figure descriptions are the same as for Figure 2. $A$, This neuron did not respond in the place phase, but responded differentially to the red block in the object phase, regardless of the required behavior or location. OI $=0.796$, $\mathrm{BI}=0.020, \mathrm{PI}=0.067 . B-D$, This neuron did not respond in the ISA task or its reversal. Thus, this neuron responded specifically in the PCA and not in the ISA task. TSI $=0.730$ 


\section{A Both-phase neuron}

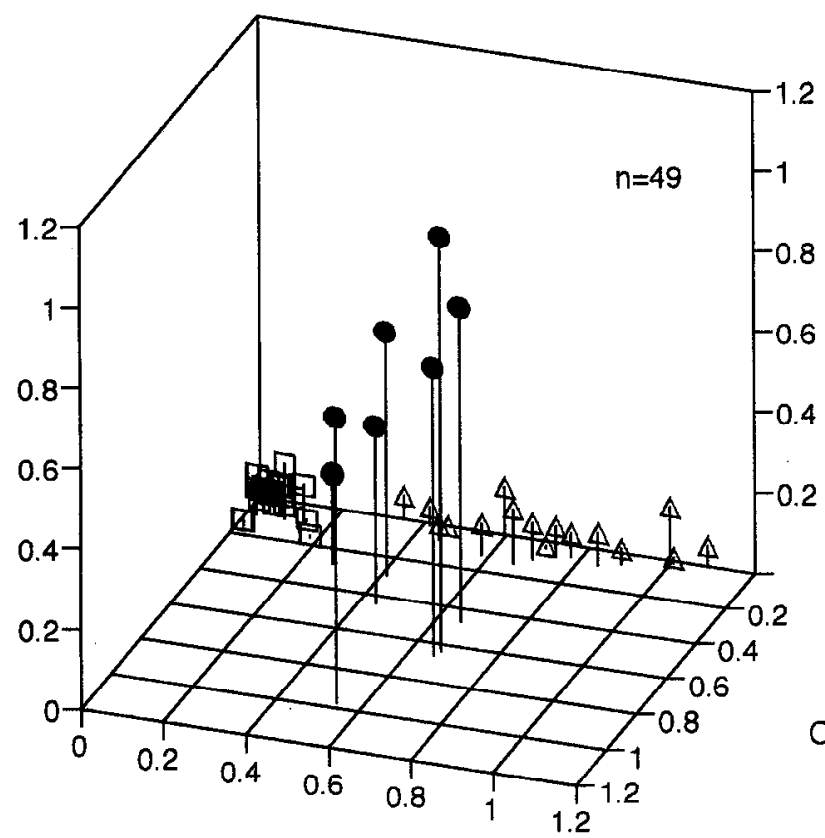

BI

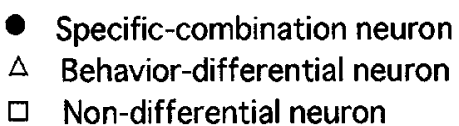

B Object-phase neuron

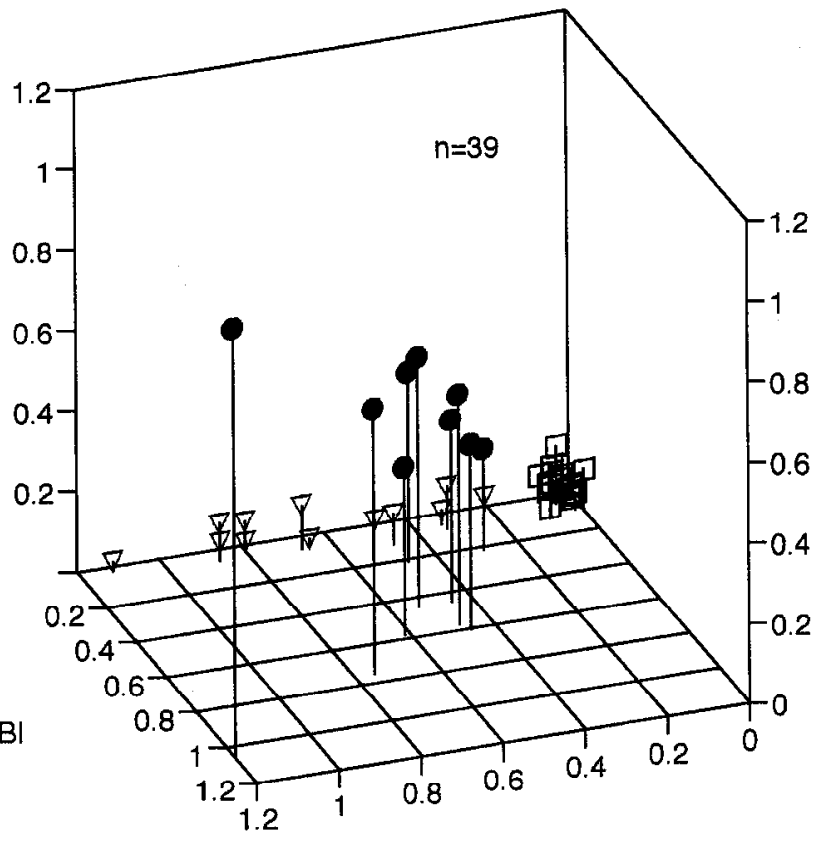

OI

\section{Specific-combination neuron}

$\nabla$ Object-differential neuron

$\square \quad$ Non-differential neuron

Figure 7. Three dimensional plots of differential response indices of both-phase and object-phase neuron populations. $A$, Both-phase neuron population $(n=49)$. OI, BI, and PI of each type of both-phase neurons are plotted in three dimensions. Nondifferential neurons $(\square)$. Behaviordifferential neurons $(\triangle)$. Specific-combination neurons $(\mathcal{O})$. $B$, Object-phase neuron population $(n=39)$. Nondifferential neurons $(\square)$. Objectdifferential neurons $(\nabla)$. Specific-combination neurons $(\mathbf{O})$.

\section{Influence of association structure and/or the subject's location on HF neuron responses}

Location of the monkey clearly affected HF neuronal responsiveness in the present study. One possibility is that location is the primary concern of the $\mathrm{HF}$ as argued by O'Keefe and Nadel (1978). Consistent with this view, association of spatial information based on the subject's location seemed to be an important determinant for two types of specific-combination neurons since neuronal responses to the same object-behavioral response as- sociation did not occur in the ISA task, which lacked spatial information. In addition, these neuronal responses were observed only in specific locations. Recently, we reported placerelated neurons in the monkey HF (Ono et al., 1991, 1993a,b), the activity of which depended on the subject's location. Using a paradigm in which the monkey could change the location of the cab while performing an operant task, we found several types of neurons, including one that changed activity when the subject changed location, and one that responded differently to

Table 1. Number, average spontaneous activity, and average response latency of each type of visually responsive neurons in the PCA task

\begin{tabular}{lccl} 
& & $\begin{array}{l}\text { Average response } \\
\text { Average spontaneous } \\
\text { activity (spikes/sec) }\end{array}$ & $\begin{array}{l}\text { latency in the } \\
\text { object phase }(\mathrm{msec})\end{array}$ \\
\hline Both-phase neurons & $49(\mathrm{E}, \mathrm{I})$ & $7.02 \pm 1.03(n=49)$ & $196.84 \pm 11.16(n=44)$ \\
$\quad$ Nondifferential & $25(\mathrm{E}=21, \mathrm{I}=4)$ & $10.76 \pm 1.42(n=25)$ & $141.90 \pm 5.01 \quad(n=21)$ \\
Behavior-differential & $16(\mathrm{E}=14, \mathrm{I}=2)$ & $2.88 \pm 0.52(n=16)$ & $228.75 \pm 8.89(n=16)$ \\
Specific-combination & $8(\mathrm{E}=8, \mathrm{I}=0)$ & $3.58 \pm 1.23(n=8)$ & $304.29 \pm 17.98(n=7)$ \\
Object-phase neurons & 39 & $6.20 \pm 1.14(n=39)$ & $222.50 \pm 14.41(n=36)$ \\
$\quad$ Nondifferential & $18(\mathrm{E}=13, \mathrm{I}=5)$ & $9.64 \pm 1.84(n=18)$ & $150.63 \pm 8.34(n=16)$ \\
Object-differential & $12(\mathrm{E}=12, \mathrm{I}=0)$ & $2.58 \pm 0.96(n=12)$ & $293.33 \pm 12.02(n=12)$ \\
Specific-combination & $9(\mathrm{E}=9, \mathrm{I}=0)$ & $3.01 \pm 0.94(n=9)$ & $297.50 \pm 11.61(n=8)$ \\
Total & 88 & $6.65 \pm 0.76(n=88)$ & $208.57 \pm 9.02 \quad(n=80)$ \\
\hline
\end{tabular}

E, excitatory; I, inhibitory. 
A Both-phase neurons

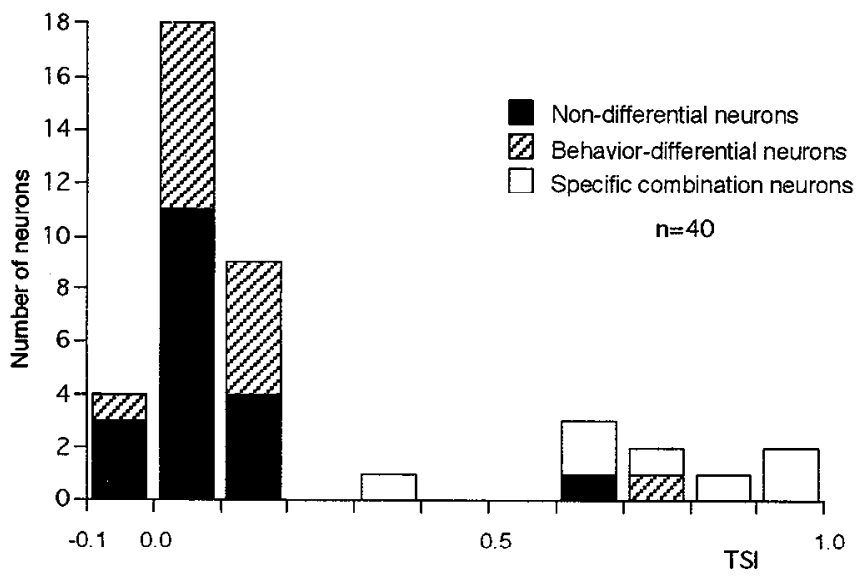

B Object-phase neurons

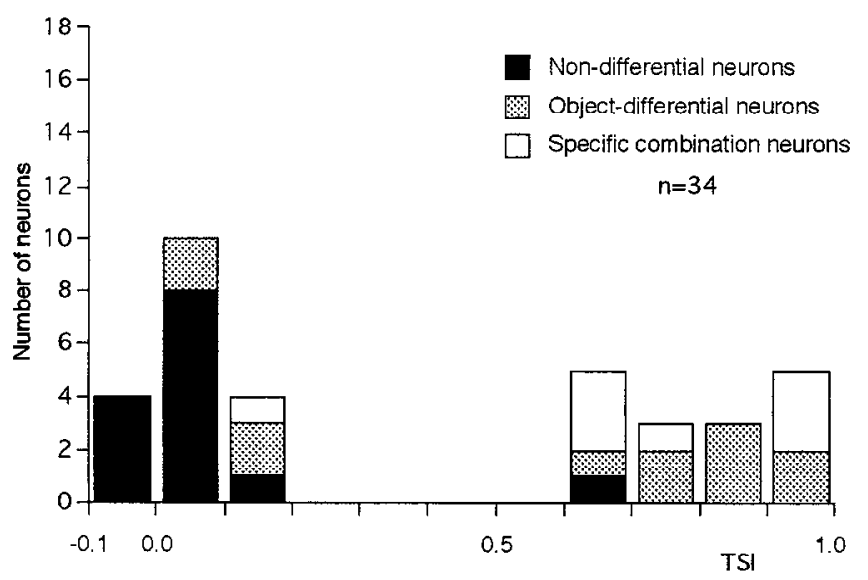

Figure 8. TSI distributions of both-phase and object-phase neuron populations. Frequency histograms of TSI. $A$, Both-phase neurons. Two groups appear, one around TSI $=0$, composed mainly of nondifferential neurons and behavior-differential neurons. The other, composed mainly of specific-combination neurons, has a few neurons with TSI higher than 0.33. $B$, Object-phase neurons. Two groups also appear here: one is around TSI $=0$, composed mainly of nondifferential neurons and a few of object-differential neurons; the other is a group with TSI higher than 0.33 , composed mainly of specific-combination and object-differential neurons.

the presented object in different locations. Activity of two types of specific-combination neurons in the present study was consistent with that of onc typc of the previously reported ncurons, since the neuronal activity of both depended on both the task cue presentation and the particular location of the subject. In particular, the object-phase activity of specific-combination bothphase neurons was correlated with place-phase activity, as in the place phase, significantly greater activity occurred at the location where the object-phase responses occurred than that at the location where no object-phase responses occurred. This neuron type had characteristics similar to those of the place and task neurons previously reported (Ono et al., 1993b). However, the present study required explicit association between place, object, and behavioral response. The present results indicate that the subject's location relates $\mathrm{HF}$ neuron responses to object-behavior association when spatial information based on the subject's location is imposed as a condition.
A. Both-phase neurons

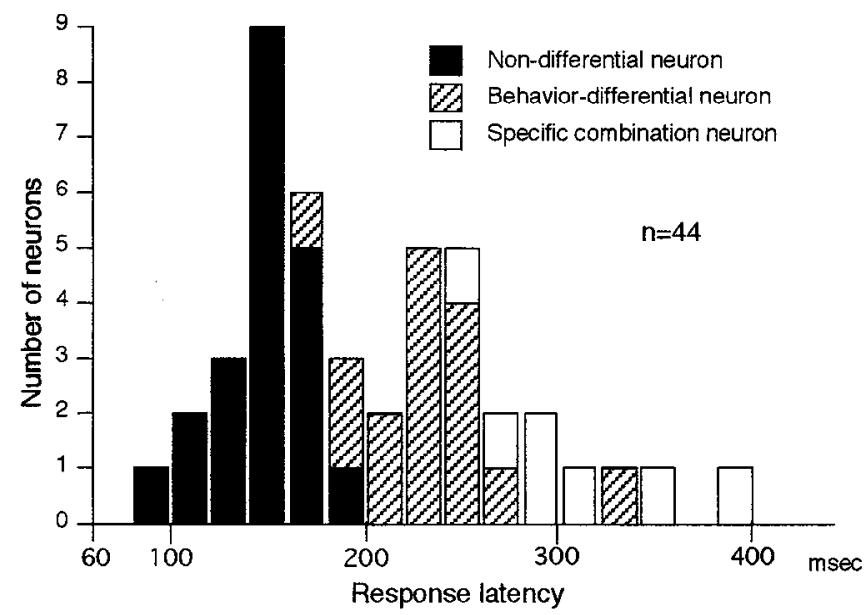

B. Object-phase neurons

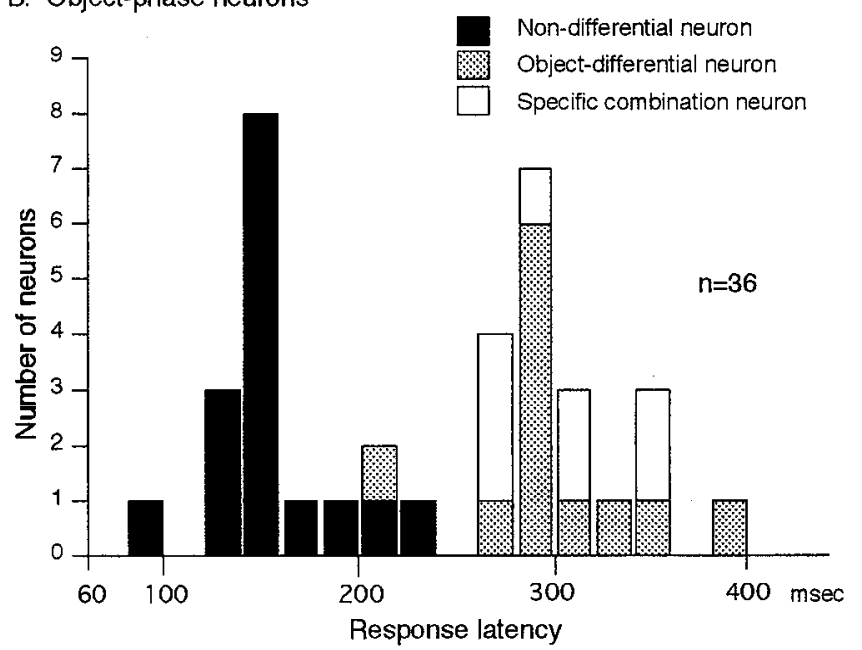

Figure 9. Response latencies of both-phase and object-phase neuron populations. Frequency histograms of response latency in the object phase of the PCA task. A, Both-phase neurons. The response latencies of nondifferential neurons are short $(141.9 \pm 5.0 \mathrm{msec}$, mean $\pm \mathrm{SEM})$, while those of specific-combination neurons are relatively long (304.3 $\pm 18.0 \mathrm{msec})$. The behavior-differential neurons are intermediate $(228.8 \pm 8.9 \mathrm{msec}) . B$, Object-phase neurons. The response latencies of nondifferential neurons are short $(150.6 \pm 8.3 \mathrm{msec})$, while those of object-differential $(293.3 \pm 12.0 \mathrm{msec})$ and specific-combination $(297.5 \pm 11.6 \mathrm{msec})$ neurons are relatively long.

The object-differential neurons also preferentially responded in the PCA task. The difference between the PCA and the ISA task was that the place phase preceded the object phase, and that the behavioral response contingency were conditional upon the place-object relation in the PCA, but there was no place phase in the ISA task. The PCA task was performed only in places I and II. Therefore, object-differential responses might also reflect covert place-object relation. That is, object-differential neurons might respond to a specific object shown only in places I and II.

Another possibility for preferential responses of this type of neurons in the PCA task is that location itself is not primary, but might be considered to be part of the condition for the PCA task, like any other nonspatial complex condition, as argued by Cohen and Eichenbaum (1992), and Sutherland and Rudy (1989). In the present study, many object-differential neuronal 
Figure 10. Locations of neurons recorded in the PCA task. Recorded neurons were located in the hippocampus proper including the subficlds CA1 ( $n$ $=82)$ and $\operatorname{CA} 3(n=100)$, the dentate gyrus $(n=95)$, the subicular complex $(n=36)$, and the parahippocampal gyrus $(n=16)$. Excitatory $(\square)$ and inhibitory ( $\square$ neurons responded in the object phase of the PCA task. Dot (-), nonresponsive neurons.

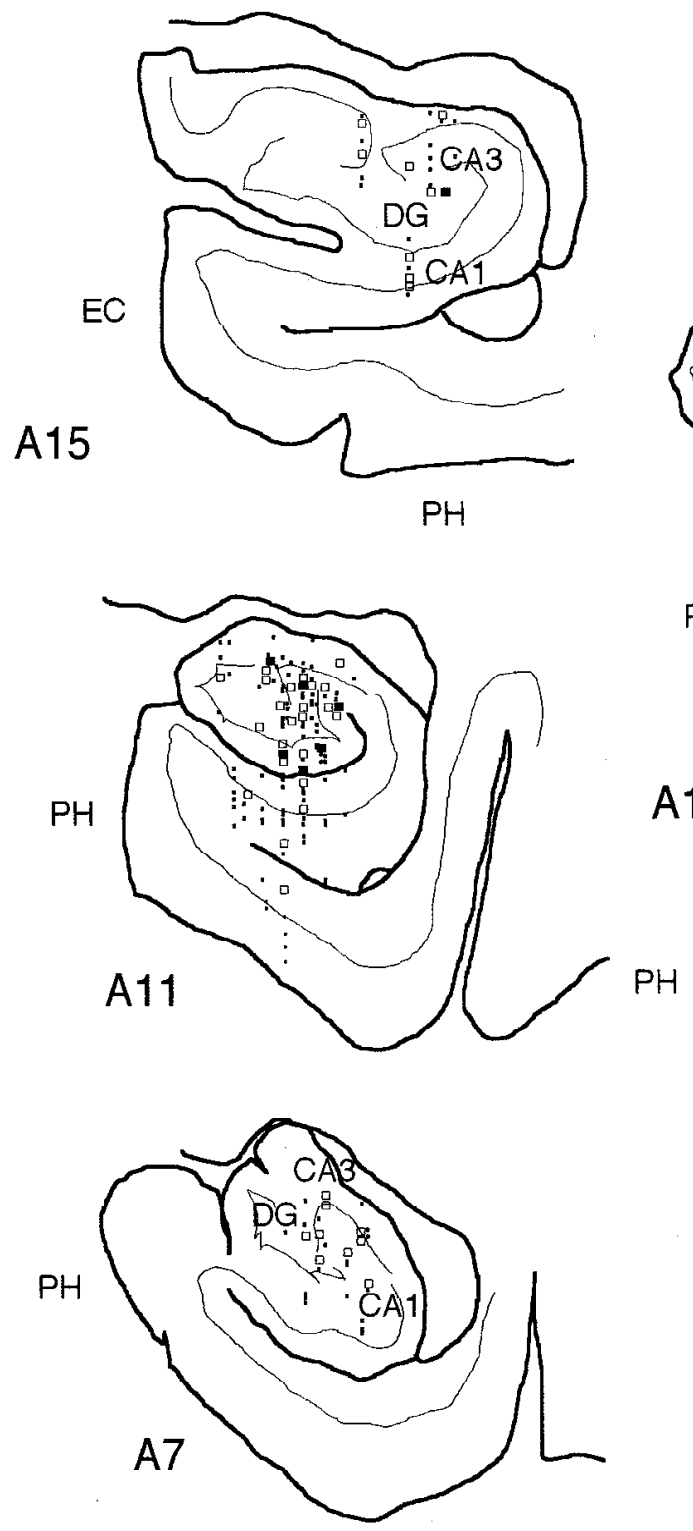

A13

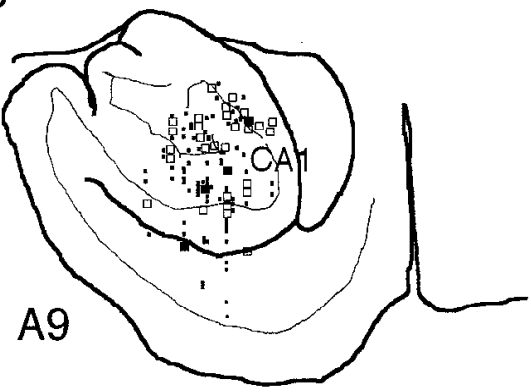

$\square \quad$ Excitatory response

- Inhibitory response

- Non-response responses that were independent of location were exclusively or predominately elicited in the PCA task. Since the PCA task is conditional and the ISA task is simple, the associative structure of the conditional PCA paradigm is more complicated than that of the ISA task. This suggests that the responses of HF neurons are highly constrained by the conditional structure of the task.

These two lines of results are not independent, but might be interpreted in a common conceptual framework of associative learning (Sutherland and Rudy, 1989; Eichenbaum et al., 1990). Recent studies have led to a consensus that the HF is one of structures essential to internal representation of space (O'Keefe and Nadel, 1978; Wilson and McNaughton, 1993). However, nonspatial memory also depends on the hippocampus (Scoville and Milner, 1957; Mishkin, 1978; Rudy and Sutherland, 1989; Zola-Morgan and Squire, 1990). This might be explained by the HF being essential to certain memory attributes that are especially prominent in, but not unique to, spatial learning and memory (Sutherland and Rudy, 1989; Eichenbaum et al., 1990). Eichenbaum and his colleagues (1990) insist that the HF is necessary when a task has highly associative demands, and intro- duction of a spatial factor into a task makes it highly associative, since spatial coding itself requires complicated associations between many stimulus items located in various positions in the environment. This might generalize the HF representation of space in terms of associative learning.

\section{Functional subpopulations in HF circuitry}

Reports of rat HF single unit studies have proposed at least two types of neurons that can be distinguished functionally (Fox and Ranck, 1981): one type includes complex spike cells that are regarded as the principal cells in HF circuitry. This type has a typically low spontaneous firing rate and fires in characteristic spike trains (complex spikes), in the manner time-locked to the theta rhythmic activity, when responding. Place cells are included in this group. The other group includes the so-called 'theta' cells. Theta cells have relatively higher spontaneous firing rates and fire in bursts that are time-locked to the theta rhythmic activity. Thus far, much evidence supports the conclusion that most theta cells are broadly tuned to space (Kubie et al., 1990) or not spatially selective (Jung and McNaughton, 1993). Theta cells 


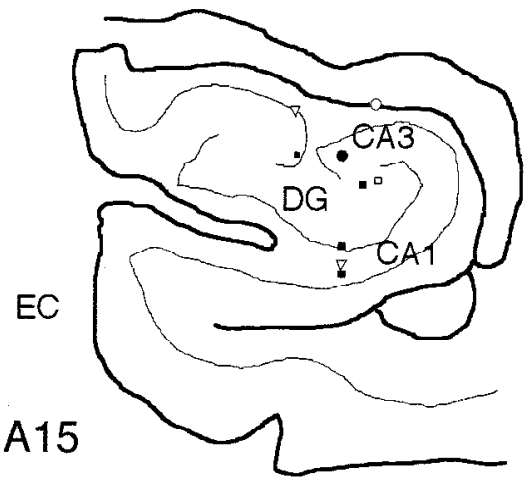

$\mathrm{PH}$
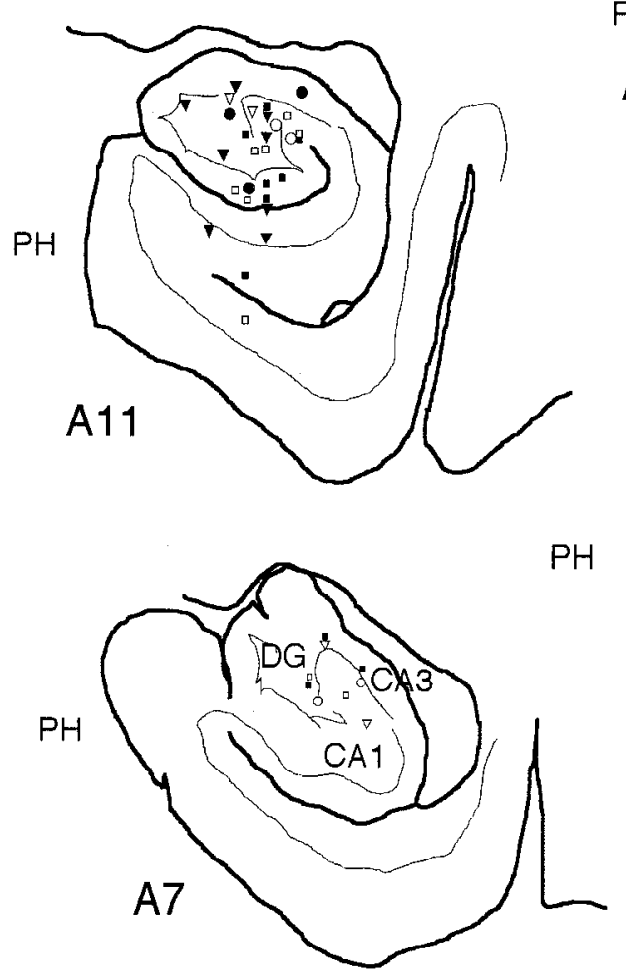

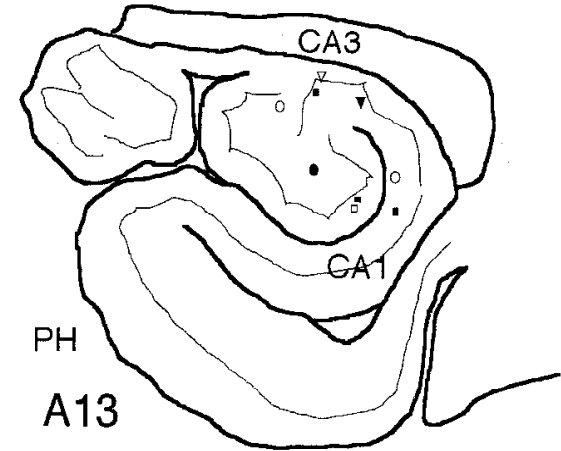

Figure 11. Locations of neuronal types analyzed for the PCA task. Nondifferential both-phase ( $\square$ ), behaviordifferential $(\boldsymbol{\nabla})$, specific-combination both-phase (1), nondifferential objectphase $(\square)$, object-differential $(\nabla)$, and specific-combination object-phase $(O)$ neurons, were diffusely distributed in the all structures of the hippocampus proper, including the subfields CA1 and CA3, the dentate gyrus, the subicular complex, and the parahippocampal gyrus.
Table 2. Number and location of each type of visually responsive neurons in the PCA task

\begin{tabular}{lrrrrrr} 
& DG & CA3 & CA1 & SUB & PH & Total \\
\hline Both-phase neurons & 14 & 18 & 14 & 3 & 0 & 49 \\
Nondifferential & 8 & 8 & 7 & 2 & 0 & 25 \\
Behavior-differential & 4 & 6 & 5 & 1 & 0 & 16 \\
Specific-combination & 2 & 4 & 2 & 0 & 0 & 8 \\
Object-phase neurons & 12 & 16 & 9 & 0 & 2 & 39 \\
Nondifferential & 6 & 6 & 4 & 0 & 2 & 18 \\
Object-differential & 2 & 7 & 3 & 0 & 0 & 12 \\
Specific-combination & 4 & 3 & 2 & 0 & 0 & 9 \\
Nonresponsive neurons & 69 & 66 & 59 & 33 & 14 & 241 \\
Total & 95 & 100 & 82 & 36 & 16 & 329
\end{tabular}

DG, dentate gyrus; SUB, subicular complex; PH, parahippocampal gyrus. have been considered to correspond to inhibitory interneurons (McNaughton and Morris, 1987).

The activity recorded from the monkey HF in the present study could not be simply classified in terms of the 'theta cell' versus the 'complex spike cell' found in rodents (Ranck, 1973; Fox and Ranck, 1981). This is consistent with some previous primate studies (Halgren et al., 1978; Rolls et al., 1989). However, it was also shown, in the present study, that a subpopulation of two types of nondifferential neurons and a subpopulation of differential neurons differed in their average spontaneous activities and their response latencies (Fig. 9, Table 1). Spike duration in these two groups also tended to be different: average spike duration (defined as interval between negative and positive peaks as in McNaughton et al., 1983) for the differential neurons was $274.00 \pm 9.17 \mu \mathrm{sec}$, while it was $220.03 \pm 6.01 \mu \mathrm{sec}$ for the nondifferential neurons (wave form was distorted since 
bandpass filtered both in the telemetry system and at the main amplifier; see Materials and Methods). Most responses of differential neurons, other than the behavior-differential neurons, occurred specifically in the PCA task, whereas most nondifferential neurons responded similarly in both the PCA and ISA tasks (see Fig. 8). There seem to be two functionally distinct object-responsive neuron types in the HF: one type includes most of the differential neurons observed in the PCA task, and the other includes most of the nondifferential neurons.

A configuration that includes two type of neurons, one with a sharply tuned profile and the other broadly responsive, is important to model HF representation of the distributed association matrix memory (Marr, 1971; McNaughton and Morris, 1987). Two categories of object-responsive neurons described in the present study may correspond to the complex spike cells and theta cells reported from rodent HF studies, although there are some differences between the firing properties of the neurons in rodents and primates. Identification of each subpopulation of neurons and their correspondence to the principal cells or the interncurons are important to the analysis of IIF circuitry; few primate unit studies satisfy these requirements.

Both differential neurons and nondifferential neurons were diffusely distributed throughout the HF However, we could find no specific-combination nor object-differential neurons in the subicular complex (Table 2), which receives outputs from the CA1 subfield where such specific neurons were observed. This sparing of specific-combination and object-differential neurons in the subicular complex in the present study might be partly ascribed to the small number of data sampled. Alternatively, it is possible that the pyramidal cells in the CAl subfield could send information directly outside the HF. It is reported the direct projections from the CA1 subfield to the entorhinal and prefrontal cortices (Amaral et al., 1984; Room and Groenewegen, 1986; Jay and Witter, 1991).

\section{Functional role of the $H F$}

It is well known that HF damage in animals and humans causes anterograde amnesia and temporally graded retrograde amnesia (Zola-Morgan et al., 1986; Zola-Morgan and Squire, 1990). Study of HF lesioned monkeys indicates that the time span over which memory depends on the HF is about 1.5 months in the case of delayed retention of object-discrimination learning (Zola-Morgan and Squire, 1990). Those studies indicated a timelimited role of the HF in mnemonic processing. The HF is likely to be involved in the early formation and storage of memory, whereas stable long-term memory may be stored in the association cortices. Furthermore, in the rat, there was evidence that memory of the association of electric shock with some specific combination of polymodal contextual stimulation was disrupted in a temporally graded manner by HF damage, although memory for the association of the same electric shock with a unimodal (tone) sensory stimulus remained intact (Kim and Fansclow, 1992). This may indicate that the temporal range of HF dependence is related to the association structure of the task (see below).

In a task that required a conditional stimulus-behavioral response association, a large population of HF neurons responded to a particular association in the task (Miyashita et al., 1989). In that study, the subject was required to acquire a conditional association between the behavioral response and an unfamiliar junk image stimulus that was changed for every session. In a task similar to this, but using familiar stimuli, neuronal responses to stimulus-behavioral response association were fairly rare (Tamura et al., 1989). These results may indicate time-limited involvement of the HF at the neuronal level.

It should be noted that the association structure implicit in the above two studies were relatively simple since they did not include a spatial factor or a conditional relation. When an association structure is highly complicated, as in the case of the PCA task, there might be no time-limited involvement of the HF, as discussed below. In the present study, we used the same completely familiar pairs of objects as stimuli in both the PCA and the ISA tasks. In these trials, neuronal responses to the same object with the same behavioral response contingency differed, depending on the nature of the task. Two types of specific-combination neurons and object-differential neurons responded more strongly in the PCA task with complex association structure than in the location-independent ISA task with simple association structure. None of the neurons tested responded in the ISA task only. These results were consistent with those in the lesion study by Kim and Fanselow (1992). In that study, deficits in rats with IIF lesions were evident only when complex combinations of contextual stimuli were presented, but not in simple conditionedstimulation tasks. Thus, it is proposed that time-limited involvement of the HF also depends on association structure and/or spatial involvement in the task. That is, as the association structure becomes more complicated, memory of such a complex association will dwell more in the HF. If so, the HF could be involved in an ongoing cognitive process in a situation that requires solving an extremely complex association structure.

As our present study shows, the HF is involved in the underlying structure of the cognitive process. In this setting, this kind of experimental manipulation of task structure may provide an useful assessment of the behavior of neurons, not only in the $\mathrm{HF}$, but also in other structures in the limbic system.

\section{References}

Amaral DG, Insausti R (1990) Hippocampal formation. In: The human nervous system (Paxinos G, ed), pp 711-755. San Diego, CA: Academic.

Amaral DG, Insausti R, Cowan WM (1984) The commissural connections of the monkey hippocampal formation. J Comp Neurol 224 307-336.

Breese CR, Hampson RE, Deadwyler SA (1989) Hippocampal place cells: stereotypy and plasticity. J Neurosci 9:1097-1111.

Cahusac PMB, Rolls ET, Miyashita Y, Niki H (1993) Modification of the responses of hippocampal neurons in the monkey during the learning of a conditional spatial response task. Hippocampus 3:2942.

Cohen NJ, Eichenbaum H (1993) Memory, amnesia and the hippocampal system. Cambridge, MA: MIT Press.

Eichenbaum H, Cohen NJ (1988) Representation in the hippocampus: what do the neurons code? Trends Neurosci 11:244-248.

Eichenbaum H, Stewart C, Morris RGM (1990) Hippocampal representation in place learning. $\mathrm{J}$ Neurosci 10:3531-3542.

Eichenbaum H, Otto T, Cohen NJ (1992) The hippocampus: what does it do? Behav Neural Biol 57:2-36.

Eichenbaum H, Otto T, Cohen NJ (1994) Two functional components of the hippocampal memory system. Behav Brain Sci, in press.

Feigenbaum JD, Rolls ET (1991) Allocentric and egocentric spatial information processing in the hippocampal formation of the behaving primate. Psychobiology 19:21-41

Felleman DJ, Van Essen DC (1991) Distributed hierarchical processing in the primate cerebral cortex. Cereb Cortex 1:1-47.

Fox SE, Ranck JB Jr (1981) Electrophysiological characteristics of hippocampal complex-spike cells and theta cells. Exp Brain Res 41: $399-410$.

Gaffan D, Harrison S (1989) Place memory and scene memory: effects of fornix transection in the monkey. Exp Brain Res 74:202-212.

Halgren E, Babb TL, Crandall PH (1978) Human hippocampal for- 
mation EEG desynchronizes during attentiveness and movement. Electroencephalogr Clin Neurophysiol 44:778-781.

Jay TM, Witter MP (1991) Distribution of hippocampal CA1 and subicular efferents in the prefrontal cortex of the rat studied by means of anterograde transport of Phaseolus vulgaris-leucoagglutinin. $\mathrm{J}$ Comp Neurol 313:574-586.

Jung MW, McNaughton BL (1993) Spatial selectivity of unit activity in the hippocampal granular layer. Hippocampus 3:165-182.

Kim JJ, Fanselow MS (1992) Modality-specific retrograde amnesia of fear. Science 256:675-677.

Kubie JL, Muller RU, Bostock E (1990) Spatial firing properties of hippocampal theta cells. J Neurosci 10:1110-1123.

Marr D (1971) Simple memory: a theory for archicortex. Philos Trans R Soc Lond [Biol] 262:23-81.

McNaughton BL, Morris RGM (1987) Hippocampal synaptic enhancement and information storage within a distributed memory system. Trends Neurosci 10:408-415.

McNaughton BL, Barnes CA, O'Keefe J (1983) The contribution of position, direction, and velocity to single unit activity in the hippocampus of freely-moving rats. Exp Brain Res 52:41-49.

Mishkin M (1978) Memory in monkeys severely impaired by combined but not by separate removal of amygdala and hippocampus. Nature 273:297-298.

Miyashita Y, Rolls ET, Cahusac PMB, Niki H, Feigenbaum JD (1989) Activity of hippocampal formation neurons in the monkey related to a conditional spatial response task. J Neurophysiol 61:669-678.

Morris RGM, Garrud P, Rawlins JNP, O'Keefe J (1982) Place navigation impaired in rats with hippocampal lesions. Nature 297:681683.

Muller RU, Kubie JL (1987) The effects of changes in the environment on the spatial firing of hippocampal complex-spike cells. J Neurosci 7:1951-1968.

O'Keefe J, Conway DH (1978) Hippocampal place units in the freely moving rat: why they fire where they fire. Exp Brain Res 31:573590 .

O'Keefe J, Dostrovsky J (1971) The hippocampus as a spatial map. Preliminary evidence from unit activity in the freely-moving rat. Brain Res 34:171-175.

O'Keefe J, Nadel L (1978) The hippocampus as a cognitive map. London: Oxford UP.

O'Keefe J, Speakman A (1987) Single unit activity in the rat hippocampus during a spatial memory task. Exp Brain Res 68:1-27.

Ono T, Nakamura K, Fukuda M, Tamura R (1991) Place recognition responses of neurons in monkey hippocampus. Neurosci Lett 121: 194-198.

Ono T, Fifukı S, Nakamura K, Nishijo H (1993a) Monkey hippocampal neuron responses related to spatial and non-spatial influence. Neurosci Lett 159:75-78.
Ono T, Nakamura K, Nishijo H, Eifuku S (1993b) Monkey hippocampal neurons related to spatial and nonspatial functions. J Neurophysiol 70:1516-1529.

Parkinson JK, Murray EA, Mishkin M (1988) A selective mnemonic role for the hippocampus in monkeys: memory for the location of objects. J Neurosci 8:4159-4167.

Ranck JB Jr. (1973) Studies on single neurons in dorsal hippocampal formation and septum of unrestrained rats $\mathrm{I}$. Behavioral correlates and firing repertoires. Exp Neurol 41:461-531.

Rolls ET, Miyashita Y, Cahusac PMB, Kesner RP, Niki H, Feigenbaum JD, Bach L (1989) Hippocampal neurons in the monkey with activity related to the place in which a stimulus is shown. J Neurosci 9:1835-1845.

Room P, Groenewegen HJ (1986) Connections of the parahippocampal cortex I. Cortical afferents. J Comp Neurol 251:415-450.

Rudy JW, Sutherland RJ (1989) The hippocampal formation is necessary for rats to learn and remember configural discriminations. Behav Brain Res 34:97-109.

Rupniak NMJ, Gaffan D (1987) Monkey hippocampus and learning about spatially directed movements. J Neurosci 7:2331-2337.

Scoville WB, Milner B (1957) Loss of recent memory after bilateral hippocampal lesions. J Neurol Neurosurg Psychiatry 20:11-21.

Squire LR, Zola-Morgan S (1991) The medial temporal lobe memory system. Science 253:1380-1385.

Sutherland RJ, Rudy JW (1989) Configural association theory: the role of the hippocampal formation in learning, memory, and amnesia. Psychobiology 17:129-144.

Tamura R, Ono T, Fukuda M, Nakamura K (1989) Responsiveness of monkey hippocampal and entorhinal neurons in learning behavior. Jpn J Physiol [Suppl] 39:S120.

Watanabe T, Niki $H$ (1985) Hippocampal unit activity and delayed response in the monkey. Brain Res 325:241-254.

Wiblc CG, Findling RL, Shapiro M, Lang EJ, Crane S, Olton DS (1986) Mnemonic correlates of unit activity in the hippocampus. Brain Res 399:97-110.

Wiener SI, Paul CA, Eichenbaum H (1989) Spatial and behavioral correlates of hippocampal neuronal activity. J Neurosci 9:2737-2763.

Wilson MA, McNaughton BL (1993) Dynamics of the hippocampal ensemble code for space. Science 261:1055-1058.

Witter MP, Groenewegen HJ, Lopes da Silva FH, Lohman AHM (1989) Functional organization of the extrinsic and intrinsic circuitry of the parahippocampal region. Prog Neurobiol 33:161-253.

Zola-Morgan SM, Squire LR (1990) The primate hippocampal formation: evidence for a time-limited role in memory storage. Science 250:288-291.

Zola-Morgan SM, Squire LR, Amaral DG (1986) Human amnesia and the medial temporal region: enduring memory impairment following a bilateral lesion limited to field CA1 of the hippocampus. J Neurosci 6:2950-2967. 